\title{
Natural Barrier Assessment and Modeling for Fish Communities in Delaware Water Gap National Recreation Area
}

Ross G. Andrew

West Virginia University

Follow this and additional works at: https://researchrepository.wvu.edu/etd

\section{Recommended Citation}

Andrew, Ross G., "Natural Barrier Assessment and Modeling for Fish Communities in Delaware Water Gap National Recreation Area" (2012). Graduate Theses, Dissertations, and Problem Reports. 379.

https://researchrepository.wvu.edu/etd/379

This Thesis is protected by copyright and/or related rights. It has been brought to you by the The Research Repository @ WVU with permission from the rights-holder(s). You are free to use this Thesis in any way that is permitted by the copyright and related rights legislation that applies to your use. For other uses you must obtain permission from the rights-holder(s) directly, unless additional rights are indicated by a Creative Commons license in the record and/ or on the work itself. This Thesis has been accepted for inclusion in WVU Graduate Theses, Dissertations, and Problem Reports collection by an authorized administrator of The Research Repository @ WVU. For more information, please contact researchrepository@mail.wvu.edu. 


\title{
Natural Barrier Assessment and Modeling for Fish Communities in Delaware Water Gap National Recreation Area
}

\author{
Ross G. Andrew \\ A Thesis Submitted to the \\ Davis College of Agriculture, Forestry, and Consumer Sciences \\ at West Virginia University \\ in partial fulfillment for the requirements \\ for the degree of \\ Master of Science \\ in \\ Wildlife and Fisheries Resources
}

\author{
Stuart A. Welsh, Ph.D., Chair \\ Michael P. Strager, Ph.D. \\ John A. Young, M.S.
}

Wildlife and Fisheries Resources Program

Division of Forestry and Natural Resources

Morgantown, West Virginia

2012

Keywords: barrier; passability; connectivity; Delaware Water Gap National Recreation Area; barrier step; functional barrier; score index; predictive modeling 


\title{
Abstract \\ Natural Barrier Assessment and Modeling for Fish Communities in Delaware Water Gap National Recreation Area
}

\begin{abstract}
Ross Andrew
Natural barriers may play an important role in structure and composition of stream fish habitat. Determining the effects of natural barriers on fish communities is important for understanding ecological processes that may occur throughout barrieraffected habitats. Additionally, modeling the likelihood of natural barrier occurrence using spatial data can reduce survey effort in the field and make management of fisheries in barrier-affected systems more efficient. I surveyed 446 natural barriers within the Delaware Water Gap National Recreation Area using a standardized field protocol to assess passability for fishes. I measured natural barriers individually based upon individual morphology and developed a scoring system to determine difficulty for fish passage. Fish communities were then sampled at 65 paired sites for richness and density upstream and downstream of natural barriers. The results were analyzed using pair-wise comparisons for upstream and downstream sites and showed significant species richness differences between sites separated by barriers while both brook and brown trout densities showed little to no differences among sites with and without barriers present. I modeled barrier occurrence across the study area using spatial data variables and developed rules criteria for prediction of natural barrier occurrence hot spots. Slope, flow accumulation number (watershed area) and soil type were found to be important for predicting natural barrier occurrence within our study area. Higher slopes increased the likelihood of natural barrier occurrence while lower drainage area had a similar effect. Soil types with highly erodible, rocky compositions associated with steep slopes also increased the odds of natural barrier incidence.
\end{abstract}




\section{Acknowledgements}

I would like to thank the WVU Division of Forestry and Natural Resources and the USGS Cooperative Fish and Wildlife Research Unit for allowing me the opportunity to attend graduate school and be a part of an excellent research group. I would like to especially say thank you to Dr. Stuart Welsh for the encouragement, advice, and guidance throughout my time at WVU. Thanks also to Dr. Mike Strager and John Young for serving on my graduate committee as well as providing invaluable guidance along the way. Also, thank you to Becky Nestor for keeping my project organized through busy field seasons of travel and offering support while on campus in Morgantown. A very large thank you goes to everyone at USGS Leetown Science Center who helped me with this project. Having a home base away from WVU was very beneficial and tons of good advice and suggestions came from everyone at the Aquatic Ecology Branch of Leetown throughout my time working on this project. A special thanks to both Tanner Haid and Dave Weller for their help in the field; and Craig Snyder, Than Hitt, John Young, and Mary Mandt Rockey for help in both the field and design of this project.

Lastly, I would like to thank my family and friends for their support and love throughout my pursuit of this degree. Special thanks go to Matthew Dunay and Beth Getty for putting up with me and my family. I am indebted to Beth Getty for her endless support and love even from halfway across the country. My Mom (Betsy), Dad (Spike), and Sister (Megan) have always been my biggest supporters and astute critics and I love them for that. 


\section{Table of Contents}

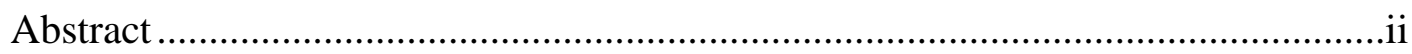

Acknowledgements............................................................................................ii

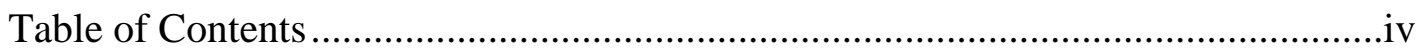

List of Tables ................................................................................................vi

List of Figures .................................................................................................

Chapter 1: Literature Review and Objectives ......................................................

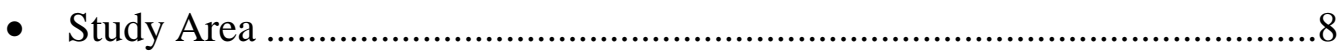

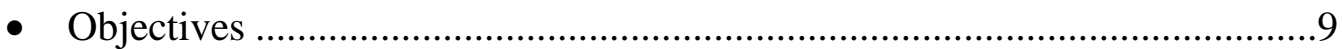

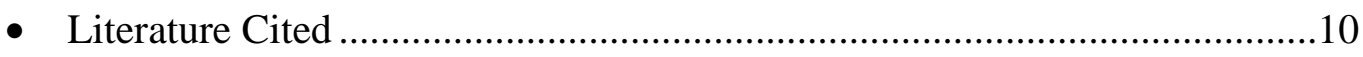

Chapter 2: Natural Barrier Effects on Trout and Fish Communities in Delaware Water Gap National Recreation Area .............................................................................14

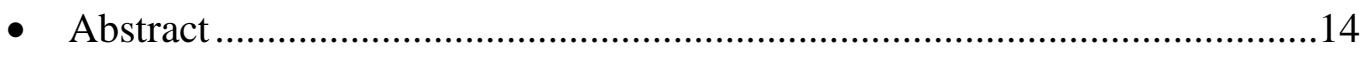

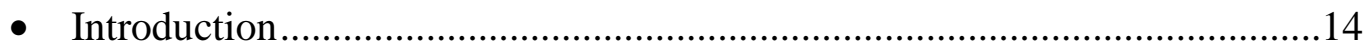

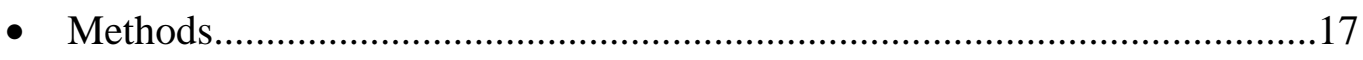

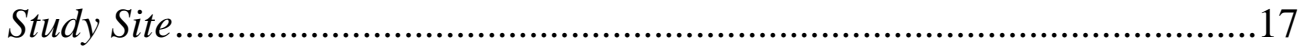

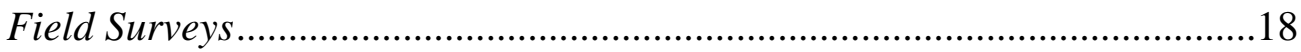

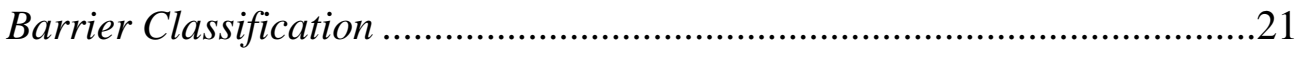

Habitat and Fish Sampling ........................................................................22

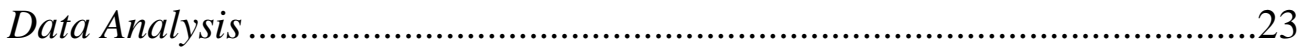

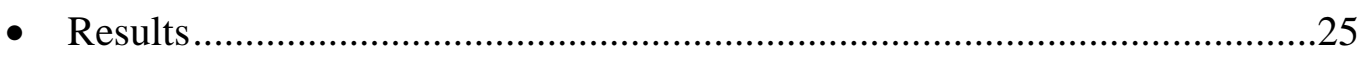

Comparison of Sites Upstream versus Downstream of Barriers .....................25

Difference Between Impounded and Non-Impounded Streams ......................26

Defining A Functional Barrier...................................................................27

Evaluation of Longitudinal Richness Patterns .............................................28

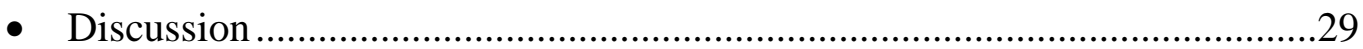

Extent of Natural Barrier Fragmentation .................................................29

Role of Other Factors Defining Fish Communities .........................................30

Limitations and Suggestions for Future Study ...............................................33

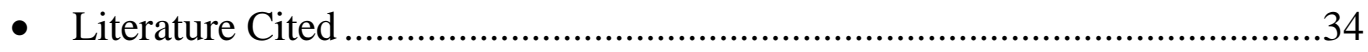


Chapter 3: Predictive Modeling of Natural Barrier Occurrence in Delaware Water Gap

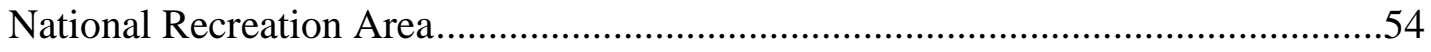

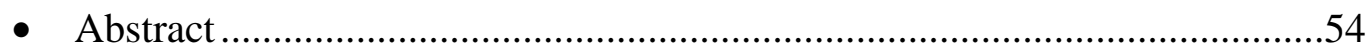

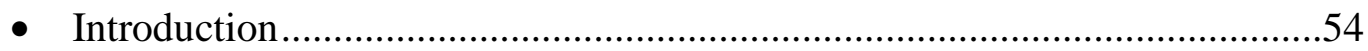

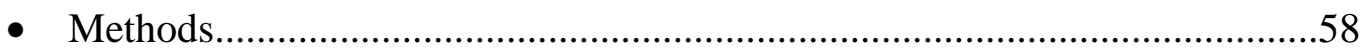

Field Surveys and Data Collection .......................................................58

Barrier Classification ........................................................................60

Predictive Modeling .......................................................................62

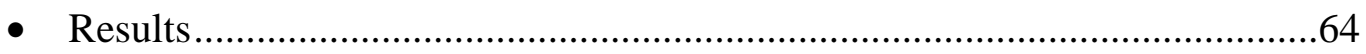

Spatial Distribution of Natural Barriers..................................................64

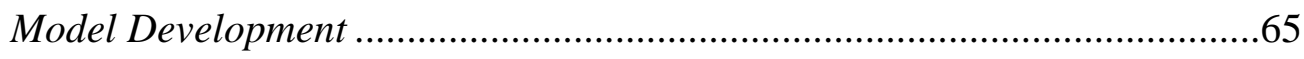

Mapping and Extrapolation of Results ....................................................66

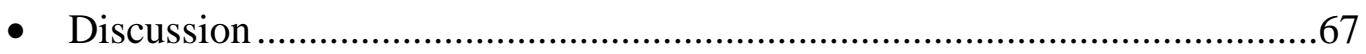

Limitations and Modeling Considerations...............................................69

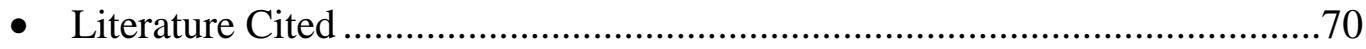




\section{List of Tables}

Table 2.1: Summary of tests for differences in biological endpoints when comparing upstream and downstream sites across the range of barrier severity levels

Table 2.2: Summary of tests for habitat differences comparing upstream and downstream sites across the range of barrier severity levels. 38

Table 2.3: Summary attribute data for watersheds sampled ................................39

Table 2.4: Summary of natural barrier occurrence within watersheds sampled.......40

Table 3.1: Summary of natural barrier occurrence within watersheds sampled.......74

Table 3.2: Comparison of barrier occurrence logistic regression models using AIC values .75

Table 3.3: Significant variable contributions to the most parsimonious barrier presence logistic regression model . .75 


\section{List of Figures}

Figure 2.1: Delaware Water Gap National Recreation Area in relation to surrounding cities and states

Figure 2.2: Presence of brook trout and brown trout in sites influenced and uninfluenced by impoundments in Delaware Water Gap National Recreation Area

Figure 2.3: Sampled species richness differences between fish sampling sites with no functional natural barrier and sites with a functional natural barrier

Figure 2.4: Sampled species richness differences between sites with a headwater impoundment present and sites with no impoundment present

Figure 2.5: Patterns of average sampled species richness in sites influenced and uninfluenced by impoundment presence

Figure 2.6: Sampled brook trout density differences between fish sampling sites with no functional natural barrier and sites with a functional natural barrier

Figure 2.7: Sampled brown trout density differences between fish sampling sites with no functional natural barrier and sites with a functional natural barrier

Figure 2.8: Comparison of average wetted width $(\mathrm{m})$ between above (upstream) and below (downstream) barrier fish sampling sites

Figure 2.9: Comparison of brook trout density between sites with influenced and uninfluenced by impoundments

Figure 2.10: Comparison of water temperature between sites influenced by impoundments and sites uninfluenced by impoundments

Figure 2.11: Comparison of average wetted width $(\mathrm{m})$ between sites influenced by an impoundment and those sites uninfluenced by impoundments

Figure 2.12: Sampled brook trout density $\left(\mathrm{fish} / \mathrm{m}^{2}\right)$ as related to water temperature at each sampling site

Figure 2.13: Sampled brown trout density $\left(\right.$ fish $\left./ \mathrm{m}^{2}\right)$ as related to water temperature at each sampling site

Figure 2.14: Mean natural barrier difficulty score and mean species richness plotted along a longitudinal gradient of sample sites moving from downstream to upstream 
Figure 2.15: Mean natural barrier difficulty score and mean brook trout density plotted along a longitudinal gradient of sample sites moving from downstream to upstream

Figure 2.16: Mean natural barrier difficulty score and mean brown trout density plotted along a longitudinal gradient of sample sites moving from downstream to upstream

Figure 3.1: Comparison between natural barrier occurrences in sites in New Jersey (NJ) versus sites in Pennsylvania (PA) 76

Figure 3.2: Map of Conashaugh Creek watershed showing application of slope rules criteria for mapping in raster calculator. .77

Figure 3.3: Map of Conashaugh Creek watershed showing application of flow accumulation rules criteria for mapping in raster calculator

Figure 3.4: Final mapped output from the raster-based rules criteria for natural barrier occurrence in Conashaugh Creek watershed 79

Figure 3.5: Final mapped output from the raster-based rules criteria for natural barrier occurrence in Van Campens Brook watershed .80 


\section{Literature Review}

Fish ecology and fisheries management may be broken down into three overarching pieces 1) biota, 2) habitat, and 3) people. The complex interactions among these three pieces are the foundations of understanding ecology and applying sound management strategies. Understanding how habitat influences fish movement and distribution is a fundamental step in understanding aquatic systems. Barriers to fish movement such as dams and road culverts are known to restrict fish movement (Thompson and Rahel 1998; Warren and Pardew 1998). Although many studies have focused on habitat fragmentation by unnatural dams and road culverts, less has been uncovered about the effects of natural barriers on fish distributions. In high gradient streams, natural barriers may easily form isolated habitats which could have a significant effect on fish communities (Powers and Orsburn 1985). Natural barriers may also act in accordance with the serial discontinuity concept (Ward and Stanford 1983) to interrupt longitudinal patterns of biota in stream systems (Vannote et al. 1980).

Lotic systems have been defined and researched using the river continuum concept (RCC) since its development by Vannote et al. (1980). The RCC illustrates the mechanisms by which physical, biological, and chemical characteristics of streams change from headwaters to mouth. Nutrients are shown to flow through the river system while adaptations occur from the biota within each respective habitat area according to their position in the continuum. The RCC relies on the idea of nutrient spiraling, which explains how nutrients are transported longitudinally as they flow through their respective nutrient cycles in stream systems (Webster 1975). These ideas help explain lotic ecosystems as an ever-changing, dynamic environment. 
Since stream ecosystems must flow naturally to fulfill the RCC, any interruption in the stream could have physical, biological, and chemical implications. Ward and Stanford (1983) proposed the serial discontinuity concept to adjust these parameters in lotic systems with interruptions caused by dams. They explained that longitudinal shifts in parameters could be caused by barriers in lotic systems. Shifts could occur in either the upstream or downstream direction and could be expressed at the population, community, or ecosystems levels.

One such issue with dammed lotic ecosystems is movement of fishes.

Downstream effects of dams have been well documented across the U.S. (Kanehl et al. 1997; Smith et al. 2000). Fragmentation by dams and impoundments has also been considered one of the greatest threats to maintenance of native fishes and waterways within the U.S. (Jackson et al. 2001). Guenther and Spacie (2006) found upstream effects of impoundments on lotic systems in Indiana to include shifts to more generalist species, as well as relative abundance of piscivores when compared to streams that were unfragmented. A similar shift in impounded streams in Texas to more generalist fish species was attributed to colonization of more intermittent habitats created by stream fragmentation (Herbert and Gelwick 2003). A study in coastal Japanese streams found higher species richness, density, and total biomass below dams while trophic dynamics were dominated by invertivores above the dams and benthic algae feeders below the dams (Katano et al. 2006). Morita and Yamamota (2002) compared white-spotted charr (Salvelinus leucomaenis) distributions above and below dams in Hokkaido, Japan and found charr upstream in all of the undammed sites and predicted localized extinctions above barriers if fish ladders were not installed. Cumming (2004) found that species 
richness in several Wisconsin streams was not as greatly affected by the presence of lowhead dams as changes in water quality and maximum stream temperature. This offers some support for fish passability of barriers which allow water to flow over them such as low-head dams. Dams may cause issues for fisheries but are not the only type of barriers that exist within stream networks.

Fishes move by both necessity and choice, to use new habitats, shelter, and food resources (Fausch and Young 1995). Some movement is driven by attraction to spawning or feeding activities while other movement is motivated by avoidance of predators, competitors, and disturbances (Fausch and Young 1995; Harvey 1991). Petty and Grossman (2004) found mobile juvenile mottled sculpin (Cottus bairdi) to grow faster than their sedentary counterparts when large adults were present, indicating intraspecific competition for resources as a driver for movement. Some movements can cover large distances of up to approximately three kilometers (Gowan and Fausch 1996).

Large distance movement of fishes contrast greatly with the restricted movement paradigm (RMP) proposed by Gerking (1959). The RMP theorized that stream fishes do not move significantly out of a specific "home range" which is defined as their normal day-to-day active range. This theory has since been challenged on the basis of biased sampling in areas where fishes are marked and subsequently recaptured, thus not allowing for movement to be detected. Gowan et al. (1994) tested this bias and found substantial movement of trout in Colorado and Wyoming using sampling at weirs and radio telemetry. Still other research has proposed that the RMP is not invalid, but incomplete; leaving out the connection between turnover rates and displacement rates in stream fish populations (Rodriguez 2002). The researchers in this study along with 
others found that stream fish populations were composed of a sedentary majority with a small percentage being highly mobile (Hesthagen 1988; Heggenes et al. 1991; Rodriguez 2002).

Brook trout (Salvelinus fontinalis) are highly mobile compared to other salmonids (Rodriguez 2002). Adams et al. (2000) found brook trout to be highly mobile in western U.S. streams, sometimes traveling up gradients as steep as $22 \%$ and barriers of 1.2 meters. Gowan and Fausch (1996) also found highly mobile brook trout in Colorado streams. They found that brook trout were more likely to move upstream than downstream and tended to move the most in early summer when spring runoff was slowing down (Gowan and Fausch 1996). Some of the brook trout moved over three kilometers in this study. Brook trout have also been found to move upstream and cause displacement of native cutthroat trout (Oncorhyncus clarki) in Colorado streams (Peterson and Fausch 2003). The researchers in this study found rapid and sometimes vast (up to two kilometers in one summer) movements of the nonnative brook trout. Brook trout are also highly mobile in their native range (Peterson and Fausch 2003). Petty et al. (2005) found mobility of brook trout in West Virginia related to spawning locations in which spawning adults moved seasonally to find the most suitable habitat. Gresswell and Hendricks (2007) found a similar pattern of seasonal movement driven by spawning in coastal cutthroat trout populations in Oregon. It is clear that movement is essential for both migratory and resident stream fishes, from both an individual survival and population persistence perspective.

Habitat connectivity is essential for fish dispersal throughout a potential range (Weins 2002; Pringle 2003). A high degree of connectivity is also representative of the 
natural state in most aquatic systems, allowing fishes to move freely without artificial fragmentation of habitat (Weins 2002). When habitat connectivity is lost due to both natural and artificial barriers, fishes lose their ability to disperse into adjacent habitats and use adjacent resources (Thompson and Rahel 1998; Warren and Pardew 1998; Adams et al. 2001; Gibson 2005; Cote et al. 2009). Roghair and Dolloff (2005) examined native brook trout movements in relation to recolonization of a stream reach damaged by debris flows and flooding and found movements commonly around 100-200 meters but up to two kilometers in attempts to recolonize the affected areas. Losses in dispersal potential can therefore lead to changes in fish populations and food web dynamics when movement is necessary for persistence (Winemiller and Jepsen 2005).

Artificial barriers such as culverts and other stream-road crossing structures can affect potential fish movement. Thompson and Rahel (1998) examined passability of two types of artificial road-stream crossing structures in rocky mountain streams. They found that rock gabions were passable by brook trout while corrugated metal pipe culverts were not passable. They attributed passability to gaps between the rocks within the gabions and concrete slabs at the outlet of the culverts which prevented a jumping pool from forming downstream. Warren and Pardew (1998) found similar results in Arkansas streams with artificial road crossing structures. Culverts showed an order of magnitude less movement than natural reaches while open-boxes and fords showed little difference in movement compared to natural reaches. They attributed these differences in movement to water velocity differences at the different types of crossings. Culverts had the highest velocities and the lowest movement while the fords and open-boxes had the lowest velocities and the highest movement. 
Natural barriers such as waterfalls have been considered fish passage barriers as well (Adams et al. 2001; Cote et al. 2009) Adams et al. (2001) found natural barriers of $17 \%$ slope and 2.5 meters in vertical height to be upstream invasion barriers for brook trout in western streams. Cote et al. (2009) examined optimal removal of barriers within aquatic networks to maximize connectivity and determined that removal of a single barrier with a large connectivity restriction would be more valuable than removal of many barriers with minimal contributions to connectivity. They treated natural barriers as having zero passability within these networks. Absolute impassability is unlikely since seasonal flow regimes and influence of human movement of fishes is often unknown.

Losses of genetic integrity and recolonization potential can be created and/or exacerbated by the presence of barriers in stream systems. Poissant et al. (2005) found signs of restricted gene flow in Canadian brook trout populations separated by barriers. Cegelski et al. (2006) found a similar result in Yellowstone cutthroat trout Oncorhynchus clarkii bouvieri where streams with the highest genetic diversity were the least modified/fragmented. Habitat fragmentation may also affect the distribution of invasive species by isolating them in certain areas and preventing their migration to other areas (Fausch et al. 2009). This could be a benefit of barrier presence since sympatric populations of native and introduced species may reduce genetic purity and increase wasted reproductive effort for the native species (Kanda et al. 2002).

Many types of barriers can contribute to habitat fragmentation including physical barriers such as culverts, waterfalls, and temperature, chemical barriers such as intolerable $\mathrm{pH}$, or biological barriers such as disease or invasive species presence. 
Previous research has been conducted to identify and accurately survey artificial barriers that prevent upstream movements of fish (Clarkin et al. 2003; Coffman 2005). Clarkin et al. (2003) developed a detailed inventory procedure for artificial barriers that has been used by the U.S. Forest Service for fish passage surveys; this inventory procedure is used in conjunction with passability models developed by Coffman (2005). Fish passability of artificial barriers is assessed using a three filter model which groups fishes into one filter based on their swimming ability and morphological characteristics (Coffman 2005). These classifications along with physical data about the crossing structure itself including perch height, slope, width, etc provide a passability ranking for individual barriers (Coffman 2005).

Predictive models have been developed that attempt to use landscape characteristics to predict where barriers are more or less likely to occur within a stream network. Poplar-Jeffers et al. (2009) investigated brook trout passage in the Cheat River watershed in West Virginia, USA. Using survey methods for slope, outlet drop, and other variables, they determined that streams with slopes of $3-5 \%$ or greater were more likely to contain impassable culvert barriers to brook trout. Kocovsky and Carline (2006) used landscape-scale factors to predict density of wild brook trout in Pennsylvania. Their models were unable to predict trout density with great precision, but their research provided some insight into landscape links to trout populations such as stream acidity and alkalinity or acid-neutralizing capacity (Kocovsky and Carline 2006). Schlosser (1995) defined three critical landscape attributes for understanding fish population dynamics in headwater streams. The first is the interaction at terrestrial-aquatic ecotones and the role these areas have in providing food, shelter, and predation risk. The second is the 
relationships between habitat patches on a larger scale and their ability to control where fishes can migrate to and from. The third and final attribute is the presence and degree of refugia that help determine fish survival as well as immigration/emigration rates.

However, predicting any stream habitat or biological assemblages requires spatially accurate landscape feature data (Wang et al. 2006).

Questions of natural barrier assessment for fish passage have seldom been addressed in detail by previous research. There are many factors to consider when measuring the relative passability of a natural barrier including stream morphology and hydraulic characteristics (Powers and Orsborn 1985). A standardized protocol for assessment of natural barriers, similar to protocols developed for culverts (Clarkin et al. 2003) will give a more complete picture of the barrier's difficulty for fish passage.

\section{Study Area}

The Delaware Water Gap National Recreation Area (DEWA) is approximately 28,000 hectares and is located in northeastern Pennsylvania and northwestern New Jersey, USA (Marion and Cole 1996). It straddles 65 kilometers of the Delaware River which also serves as the border between the two states (Figure 2.1). The area is operated by the National Park Service within the U.S. Department of the Interior. The habitats within the area are diverse and include mountainous, rocky ridges along with forested hemlock ravines and the large river floodplain. The area has been previously settled and used for small farms which were subsequently abandoned, leaving a high number of relic farm ponds and dammed streams. Recently, the area has been resettled as low density residential with a number of ponds constructed for runoff retention or simply as ornamental ponds. Many of the streams within the park are influenced by these 
impoundments which create thermal and biological anomalies. The geology includes the erodible shale Pocono escarpment on the Pennsylvania side and several steep, rocky ridges that are part of the more resistant sandstones of the Kittatinny Mountain range on the New Jersey side. The river valley sits between the physiographic provinces of the Pocono Plateau on the west and the Valley and Ridge to the east (Epstein 2006). Softer shale and limestone deposits underlie the river valley while the mountainous ridges on either side are made up of harder sandstone (Epstein 2006). These geologic differences between erodible and non-erodible rock types could help explain the distribution of fishes in conjunction with passage needs (Nelson et al. 1992). The elevation ranges from 19 to $489 \mathrm{~m}$ within the park boundary. The study area is classified as a humid continental climate zone with a predominantly warm summer. Winters are cold and snowy with intermittent freezing and thawing. The mean annual precipitation for the study area ranges from 101.9-127 cm (Natural Resources Conservation Service) with an average annual temperature between $7.22-10^{\circ} \mathrm{C}$ (National Climatic Data Center).

\section{Objectives}

The first objective of this study was to establish a standardized field protocol for assessment of natural barrier fish passability for resident stream salmonids. This field method was then used to survey natural barriers and define their relative difficulty for fish passage of those resident stream salmonids. The second objective was to identify a barrier difficulty level which impacts fish assemblages within the study area. The third objective was to identify physical habitat parameters and thresholds for those barriers that impact fish assemblages. These parameters were then used to address the fourth objective, creation of predictive models for functional natural barrier occurrence using 
logistic regression modeling. The protocol for assessing natural barriers should yield some agreement with the fish collection data and show some measurable biological response to natural barrier presence. By creating these predictive models and field protocols, we hope to help reduce the amount of field surveys necessary to get an accurate measure of connectivity across a studied landscape. By classifying areas prior to field surveys, researchers and agencies can save time and money by prioritizing their efforts for conservation and management.

\section{Literature Cited}

Adams, S.B., C.A. Frissell, and B.E. Rieman. 2001. Geography of invasion in mountain streams: consequences of headwater lake fish introductions. Ecosystems: 296307.

Adams, S.B., C.A. Frissell, and B.E. Rieman. 2000. Movements of nonnative brook trout in relation to stream channel slope. Transactions of the American Fisheries Society 129: 623-638.

Cegelski, C. C., M. R. Campbell, and K. A. Meyer. 2006. Multiscale genetic structure of Yellowstone cutthroat trout in the upper Snake River basin. Transactions of the American Fisheries Society 135: 711-726.

Clarkin, K., A. Connor, M.J. Furniss, B. Gubernick, M. Love, K Moynan, and S.W. Musser. 2003. National inventory and assessment procedure for identifying barriers to aquatic organism passage at road-stream crossings. U.S. Forest Service, San Dimas, CA.

Coffman, J.S. 2005. Evaluation of a predictive model for upstream fish passage through culverts. James Madison University.

Cote, D., D.G. Kehler, C. Bourne, and Y.F. Weirsma. 2009. A new measure of longitudinal connectivity for stream networks. Landscape Ecology 24: 101-113.

Cumming, G. S. 2004. The impact of low-head dams on fish species richness in Wisconsin, USA. Ecological Applications 14: 1495-1506.

Dunham, J. B., M. M. Peacock, B. E. Rieman, R. E. Schroeter, and G. L. Vinyard. 1999. Local and geographic variability in the distribution of stream-living Lahontan cutthroat trout. Transactions of the American Fisheries Society 128: 875-889.

Epstein, J. B. Geology of Delaware Water Gap National Recreation Area, New JerseyPennsylvania. Excursions in Geology and History: Field Trips in the Middle Atlantic States. Boulder, CO: Geological Society of America, 2006. 47-64. Print. ESRI 2011. ArcGIS Desktop: Release 10. Redlands, CA: Environmental Systems Research Institute. 
Fausch, K. D., B. E. Rieman, J. B. Dunham, M. K. Young, and D. P. Peterson. 2009. Invasion versus isolation: trade-offs in managing native salmonids with barriers to upstream movement. Conservation Biology 23: 859-870.

Fausch, K. D. and M. K. Young. 1995. Evolutionary significant units and movement of resident stream fishes: a cautionary tale. Pages 360-370 in J. L. Nielsen, editor. Evolution and the aquatic system: defining unique units in population conservation. American Fisheries Society, Symposium 17, Bethesda, Maryland.

Gerking, S.D. 1959. The restricted movement of fish populations. Biological Reviews 34: 221-242.

Gibson, R. J., R. L. Haedrich, and C. M. Wernerheim. 2005. Loss of fish habitat as a consequence of inappropriately constructed stream crossings. Fisheries 30: 10-17.

Gowan, C. and K.D. Fausch. 1996. Mobile brook trout in two high-elevation Colorado streams: re-evaluating the concept of restricted movement. Canadian Journal of Fisheries and Aquatic Sciences 53: 1370-1381.

Gowan, C., M.K. Young, K.D. Fausch, and S.C. Riley. 1994. Restricted movement in resident stream salmonids: a paradigm lost? Canadian Journal of Fisheries and Aquatic Sciences 51: 2626-2637.

Gresswell, R. E., and S. R. Hendricks. 2007. Population-scale movement of coastal cutthroat trout in a naturally isolated stream network. Transactions of the American Fisheries Society 136: 238-253.

Guenther, C. B., and A. Spacie. 2006. Changes in fish assemblage structure upstream of impoundments within the upper Wabash River basin, Indiana. Transactions of the American Fisheries Society 135: 570-583.

Harvey, B. C. 1991. Interactions among stream fishes: predator-induced habitat shifts and larval survival. Oecologia 87: 29-36.

Heggenes, J., T.G. Northcote, and A. Peter. 1991. Spatial stability of cutthroat trout (Oncorhynchus clarki) in a small, coastal stream. Canadian Journal of Fisheries and Aquatic Sciences 48: 757-762.

Herbert, M. E., and F. P. Gelwick. 2003. Spatial variation of headwater fish assemblages explained by hydrologic variability and upstream effects of impoundment. Copeia 2003: 273-284.

Hesthagen, T. 1988. Movements of brown trout, Salmo trutta, and juvenile Atlantic salmon, Salmo salar, in a coastal stream in northern Norway. Journal of Fish Biology 32: 639-653.

Jackson, D. A., P. R. Peres-Neto, and J. D. Olden. 2001. What controls who is where in freshwater fish communities - the roles of biotic, abiotic, and spatial factors. Canadian Journal of Fisheries and Aquatic Sciences 58: 157-170.

Kanda, N., R.F. Leary, and F.W. Allendorf. 2002. Evidence of introgressive hybridization between bull trout and brook trout. Transactions of the American Fisheries Society 131: 772-782.

Kanehl, P.D., J. Lyons, and J.E. Nelson. 1997. Changes in the habitat and fish community of the Milwaukee River, Wisconsin, following removal of the Woolen Mills Dam. North American Journal of Fisheries Management 17: 387-400.

Katano, O., T. Nakamura, S. Abe, S. Yamamoto, and Y. Baba. 2006. Comparison of fish communities between above- and below-dam sections of small streams; barrier effect to diadromous fishes. Journal of Fish Biology 68: 767-782. 
Kocovsky, P. M., and R. F. Carline. 2006. Influence of landscape-scale factors in limiting brook trout populations in Pennsylvania streams. Transactions of the American Fisheries Society 135: 76-88.

Kondratieff, M.C. and C.A. Myrick. 2006. How high can brook trout jump? A laboratory evaluation of brook trout jumping performance. Transactions of the American Fisheries Society 135: 361-370.

Marion, J.L, and D.N. Cole. 1996. Spatial and temporal variation in soil and vegetation impacts on campsites. Ecological Applications 6: 520-530.

Morita, K. and S. Yamamoto. 2002. Effects of habitat fragmentation by damming on the persistence of stream-dwelling charr populations. Conservation Biology 16: $1318-1323$.

Peterson, D.P. and K.D. Fausch. 2003. Upstream movement by nonnative brook trout (Salvelinus fontinalis) promotes invasion of native cutthroat trout (Oncorhynchus clarki) habitat. Canadian Journal of Fisheries and Aquatic Sciences 60: 15021516.

Petty, J.T., and G.D. Grossman. 2004. Restricted movement by mottled sculpin (pisces: cottidae) in a southern Appalachian stream. Freshwater Biology 49: 631-645.

Petty, J.T., P. J. Lamothe, and P. M. Mazik. 2005. Spatial and seasonal dynamics of brook trout populations inhabiting a central Appalachian watershed. Transactions of the American Fisheries Society 134: 572-587.

Poissant, J., T. W. Knight, and M. M. Ferguson. 2005. Nonequilibrium conditions following landscape rearrangement: the relative contribution of past and current hydrological landscapes on the genetic structure of a stream-dwelling fish. Molecular Ecology 14: 1321-1331.

Poplar-Jeffers, I.O., J.T. Petty, J.T. Anderson, S.J. Kite, M.P. Strager, and R.H. Fortney. 2009. Culvert replacement and stream habitat restoration: implications from brook trout management in an Appalachian watershed, USA. Restoration Ecology 17: 404-413.

Powers, P.D. and J.F. Orsburn. 1985. Analysis of barriers to upstream fish migration: an investigation of the physical and biological conditions affecting fish passage success at culverts and waterfalls. Final Project Report for Bonneville Power Administration. Albrook hydraulics laboratory - Washington State University.

Pringle, C. 2003. What is hydrologic connectivity and why is it important? Hydrological Processes 17: 2685-2689.

Rodriguez, M. A. 2002. Restricted movement in stream fish: the paradigm is incomplete, not lost. Ecology 83: 1-13.

Roghair, C. N., and C. A. Dolloff. 2005. Brook trout movement during and after recolonization of a naturally defaunated stream reach. North American Journal of Fisheries Management 25: 785-790.

Schlosser, I. J. 1995. Critical landscape attributes that influence fish population dynamics in headwater streams. Hydrobiologia 303:71-81.

Smith, L.W., E. Dittmer, M. Prevost, and D.R. Burt. 2000. Breaching of a small irrigation dam in Oregon: a case history. North American Journal of Fisheries Management 20: 205-219. 
Thompson, P.D. and F.J. Rahel. 1998. Evaluation of artificial barriers in small rocky mountain streams for preventing the upstream movement of brook trout. North American Journal of Fisheries Management 18: 206-210.

Vannote, R.L., G.W. Minshall, K.W. Cummins, J.R. Sedell, and C.E. Cushing. 1980. The river continuum concept. Canadian Journal of Fisheries and Aquatic Sciences 37: $130-137$.

Wang, L., P. Seelbach, and R. M. Hughes. 2006. Introduction to landscape influences on stream habitats and biological assemblages. American Fisheries Society Symposium 48: 1-23.

Ward, J.V. and J.A. Stanford. 1983. The serial discontinuity concept of lotic ecosystems. Pages 29-43 in T.D. Fontaine III and S.M. Bartell, editors. Dynamics of lotic ecosystems. Ann Arbor Science, Ann Arbor, Michigan.

Warren, M. L., Jr., and M. G. Pardew. 1998. Road crossings as barriers to small-stream fish movement. Transactions of the American Fisheries Society 127: 637-644.

Webster, J.R. 1975. Analysis of potassium and calcium dynamics in stream ecosystems on three southern Appalachian watersheds of contrasting vegetation. Ph.D. Thesis, University of Georgia, Athens.

Weins, J.A. 2002. Riverine landscapes: taking landscape ecology into the water. Freshwater Biology 47: 501-515.

Winemiller, K.O. and D.B. Jepsen. 2005. Effects of seasonality and movement on tropical river food webs. Journal of Fish Biology 53: 267-296. 


\title{
Chapter 2
}

\section{Natural Barrier Effects on Trout and Fish Communities in Delaware Water Gap National Recreation Area}

\begin{abstract}
Natural barriers within stream systems create fragmented habitat areas for most fishes. Fragmented habitat makes it difficult for fishes to find resources and suitable areas for spawning and refuge. The objectives of this study were 1) to establish a standardized system of natural barrier assessment for resident stream salmonid passage difficulty and 2) to examine biological responses to natural barrier presence at the species and community levels. Within selected watersheds, 65 paired sites were selected and sampled upstream and downstream of natural barriers. For natural barrier classification, a standardized scoring system was created for each step of each barrier. For each natural barrier, every step within that barrier would receive points based on its vertical drop and slope. Comparisons were made using t-tests or Mann-Whitney tests between upstream and downstream barrier sites with the full range of barrier severities being represented. Barrier effects were examined at both the reach and watershed scale to detect differences in species richness and trout densities. Also, habitat variables were compared among sites to examine the influence of habitat conditions on fish communities. Barrier effects on species richness were significant overall $(\mathrm{P}=0.031)$, while overall effects on both brook (Salvelinus fontinalis) and brown trout (Salmo trutta) densities were insignificant $(\mathrm{P}=0.961$ and 0.079 respectively). These results indicate that natural barriers may help define dispersal boundaries for less-capable swimming species but not the trout species of interest in this study area. Identifying the effects of natural barriers on trout and other fish communities can be valuable for management as they pertain to stream fish population dynamics and overall ecosystem theory.
\end{abstract}

\section{Introduction}

When natural barriers are present within a stream system, they may create fragmented habitat areas for fishes that cannot pass particular barriers. Fragmented habitat makes it difficult for fishes to find resources and suitable areas for spawning and refuge. Fragmentation is particularly pronounced in aquatic systems where there are very limited options for alternative movement (Fagan 2002). Natural barriers may fit into Ward and Stanford's (1983) serial discontinuity concept as a way to help understand longitudinal shifts in fish communities within lotic systems. 
Natural barriers can be defined as waterfalls, chutes, cascades or any combination of these within a water course (Powers and Orsburn 1985). A waterfall is defined as an entity in which a water course falls from a ledge, breaking contact with the substrate for some period (Mabin 2000). A chute or slide is a steep section of mostly smooth substrate which the water remains in contact with throughout its descent (Powers and Orsburn 1985). A cascade is on the spectrum between a waterfall and chute, with small breaks between drops and pools that occur while maintaining an overall high slope and turbulent water surface (Powers and Orsburn 1985).

Natural barriers create unique challenges for fish passage. In the upstream direction there is a challenge associated with vertical drops of waterfalls and steep slopes of cascades and chutes. There is also the challenge of increased flow at natural barriers since they often occur at constricted parts of the stream channel (Powers and Orsburn 1985). Passing natural barriers in a downstream direction also presents challenges. Increased flows and associated forces pushing fishes off of steep drops into unknown substrate below can cause bodily harm and even death. Depending on the structure of the natural barrier, a plunge pool may offer protection from downstream falls and may also provide a resting zone before attempting to proceed in the upstream direction (Powers and Orsburn 1985).

Fish assemblages are undoubtedly affected by many factors within their environments including habitat suitability (Brown et al. 2000), competition dynamics (Fausch and White 1981; Petty and Grossman 2004), and reproductive capacity (Gillenwater et al. 2006; Isaak et al. 2007). Analysis of natural barrier effects on stream fish assemblages can help explain limitations for fish movement and therefore access to 
available habitat for colonization. Habitats fragmented with a high density of barriers would therefore be less suitable for movement and colonization than habitat with few barriers. Even the highest quality habitats are of little use if they are severely fragmented. Fishes that exhibit competitive interactions such as brown trout Salmo trutta and brook trout Salvelinus fontinalis are greatly influenced by available habitat since optimal feeding and refuge locations are scarce (Fausch and White 1981; Bozek and Hubert 1992). Movement of fishes is often important for spawning (Gresswell and Hendricks 2007; Isaak et al. 2007) and would surely be influence by presence of barriers.

Brook trout, the focal species of this study, is a coldwater salmonid found mostly in small, headwater streams (Page and Burr 1991). The species requires cooler water temperatures and is rarely found in waters above $22^{\circ} \mathrm{C}$ (Eastern Brook Trout Joint Venture 2005). Deforestation and competition with introduced species throughout their native range has reduced many native populations and imperiled most others (Hudy et al. 2008). This species is of special concern because of its importance as a native sport fish in the eastern United States. It is the state fish of nine eastern states and is very popular among recreational anglers.

Brook trout are known to be highly mobile within stream habitats in the western (Adams et al. 2000; Gowan and Fausch 1996) and eastern (Petty et al. 2005) United States. Sometimes within-stream movements can cover up to three kilometers (Gowan and Fausch 1996). Brook trout have been found to move upstream and cause displacement of native cutthroat trout Oncorhynchus clarki in Colorado streams (Peterson and Fausch 2003). Similar displacement has occurred in eastern parts of the country with rainbow trout Oncorhynchus mykiss (Larson and Moore 1985) and brown trout (Fausch 
and White 1981) displacing brook trout. Brown trout have also been shown to displace native fish species through predation downstream of waterfalls in New Zealand streams (Townsend and Crowl 1991). Other research has shown that movements of sympatric native and non-native trout populations fluctuate naturally over time and are likely not severe restrictions on the movement range of native species (Strange and Habera 1998). Brook trout will move seasonally to find the most suitable habitats for spawning or feeding (Petty et al. 2005). Natural barriers may cause interruption in these movements, forcing fishes to live in sub-optimal habitats or co-exist with competitors. On the contrary, barriers may act as a way to keep non-native species out of native species habitats, thereby helping to preserve the natural ecosystem (Fausch and Young 1995). Brook trout are strong swimmers, and are less affected by barrier than other species within stream fish communities. Therefore, it is important to assess natural barrier effects on fisheries from both a species and community perspective. This study will focus on trout species but also address implications for the fish communities as a whole. Natural barrier assessment should also take into consideration the spatial arrangement or density of barriers within a stream system since this may help direct fish assemblages into certain areas.

The objectives of this study were 1) to establish a standardized system of natural barrier assessment for resident stream salmonid passage difficulty and 2) to examine biological responses to natural barrier presence at the species and community levels.

\section{Methods}

Study Site 
Within Delaware Water Gap National Recreation Area, 17 watersheds were randomly selected for natural barrier surveying. These watersheds ranged in size, stream order, geology, and slope. These watershed characteristics are summarized in Table 2.3 and listed according to respective watershed. However, only 16 of these watersheds were selected for fish sampling due to lack of available habitat to sample in one of the watersheds. Of the 16 remaining watersheds, 12 were influenced by impoundments immediately upstream of the park boundary. These impoundments undoubtedly affect the downstream conditions for fish in many ways, and were treated as an important determinant for fish assemblages.

Within selected watersheds, 65 paired sites were selected and sampled for fish upstream and downstream of natural barriers. Of these 65 pairs of sampling sites, 46 occurred in watersheds with an upstream impoundment and 19 occurred in watersheds without an impoundment. Pairs of sampling sites were chosen wherever there was enough stream length to conduct sampling upstream and downstream of barriers, resulting in a range of barrier difficulties being covered in the sampling.

\section{Field Surveys}

We conducted field surveys of natural barriers from 28 June to 30 July 2010 and 6 June to 26 July 2011. We selected sites using two different methods. First, we selected sites across a stream slope gradient using GIS and digital elevation models (DEMs) at $1 \mathrm{~m}^{2}$ resolutions. The DEM was created using LiDAR data acquired by Robinson Aerial Surveys, Inc. by way of the Federal Emergency Management Agency (FEMA). The LiDAR data were acquired in April of 2008 using a nominal point spacing of 1.4 meters with a point density of 0.6. The LiDAR data were collected using accuracy standards 
suitable for an inherent image scale of 1:1200 which the use of the DEM was at variable map scales. A DEM was created from the LiDAR point returns using TiFFs 6.0 LiDAR processing software by John Young at USGS Leetown Science Center (personal communication March 30, 2012). We used the DEM in a GIS to identify raster grid cells of rapidly changing elevation and slope along stream flow lines. These grid cells were classified into six categories of slope percentage $(0-3 \%, 3-5 \%, 5-12 \%, 12-17 \%, 17-$ $20 \%$, and 20-100\%). We selected these categories based upon literature-derived values for stream slope tolerances of salmonids (Adams et al. 2000, Adams et al. 2001 and Clarkin et al. 2003). A target of approximately 15 barriers from each of six slope categories $(n=90)$ were randomly selected for surveying, but 93 sites were actually surveyed.

In addition to the randomly selected stream slope strata, 17 randomly selected watersheds were intensively surveyed to coincide with fish sampling. These 17 watersheds were randomly selected from a potential 48 within the park and stratified by characteristics of elevation, geology, stream order, and stream slope. We conducted the intensive surveys by walking up (or down) a particular watershed and measuring every natural barrier found. Among these 17 watersheds, an additional 353 barrier surveys were conducted, bringing the total number of natural barrier surveys within the park to 446. By selecting sites in these two different ways, we could see the smaller barriers that may have been missed by the LiDAR site selection and better understand the limitations of this selection technique while getting a view of natural barriers throughout different watersheds. 
Each natural barrier survey was done in a series of steps. The first step was the definition of the location of the barrier within the stream and assessment of the barrier's permanence. This was done to rule out small debris jams within the stream which could act as temporary barriers to fish passage. We would then define the barrier type based upon its physical appearance. We defined barriers as waterfalls, cascades, or chute/slides according to previous research definitions of each (Powers and Orsburn 1985; Mabin 2000). Each barrier was also given a unique alphanumeric identification typically associated with its location within a given watershed.

The second step involved collection of general site information including water temperature, $\mathrm{pH}$, and barrier material such as bedrock, boulder, etc. We also took a digital photograph of the site and recorded its exact location using a Trimble GeoXT global positioning system (GPS). Additionally, we recorded locations on a handheld Garmin GPS to act as a back-up to the Trimble location points. Any interesting site features were noted including the presence of fish or specific attributes of the barrier itself.

The third step was comprised of a physical survey of the natural barrier to determine its relative difficulty for fish passage. These surveys were conducted with a Leica Geosystems DISTO D8 laser distance meter. The DISTO laser distance meter would be set up on a tripod immediately downstream of a natural barrier and steps would be measured using the slope and height function. This function could assess both the slope and height of a barrier step while taking into account the distance the tripod was set up from the barrier itself. The procedure was dependent on the type of barrier being surveyed. For example, chute/slide barriers, which do not require vertical leaps for fish 
passage, were measured in terms of slope and distance. In contrast, waterfalls or cascades were measured in terms of vertical height of each step along with that step's slope since most steps were not absolutely vertical. Depth of jump/resting pools were also recorded within a half meter of the associated barrier step to represent the likely jumping point for a fish attempting to pass the barrier in an upstream direction. A barrier step was defined by the presence of a resting pool before some vertical or highly sloped component of the barrier. We defined a resting pool as a mostly flat area with enough surface area to support an adult fish of the desired species. Resting pool size and depth varies naturally as the discharge of the stream changes seasonally. Therefore, resting pools cannot be completely ascertained but must be selected based on adequate area for the desired species. These surveys lead to the classification of each barrier based upon its severity or relative difficulty for fish passage.

\section{Barrier Classification}

Variation in stream morphology and species perception of barriers creates challenges in barrier classification. To standardize decisions of barrier classification, we used the maximum value for brook trout jump height as found by Kondratieff and Myrick (2006) as the minimum qualification for a measurable barrier. Maximum jump heights

for brook trout are based on the depth of the resting pool $(0.435 \mathrm{~m}$ and $0.735 \mathrm{~m}$ for resting pools of $<10 \mathrm{~cm}$ and $\geq 40 \mathrm{~cm}$, respectively; Kondratieff and Myrick 2006). Maximum passable slopes for brook trout are based upon the maximum values found in literature between sustained brook trout populations and the maximum slope and distance brook trout may travel in a short burst of swimming/leaping (Adams et al. 2000; Adams et al. 2001; Clarkin et al. 2003; and Dunham et al. 1999). We averaged the values found for 
each group and estimated a maximum passable slope of $20 \%$ over a distance of 20 meters or less and $11.5 \%$ with no distance limit. Maximum slopes were used to calculate barrier difficulty when there was adequate water depth for a fish to swim through the barrier; otherwise vertical jump height was used.

For natural barrier classification, a standardized scoring system was created for each step of each barrier. For each step of a natural barrier, the step would receive points based on its vertical drop and slope. For the vertical drops: $<0.735 \mathrm{~m}=1$ point, $>0.735 \mathrm{~m}$ $<2 \mathrm{~m}=5$ points, and $>2 \mathrm{~m}=10$ points. For the slopes: $0-11.5 \%=1$ point, $11.5-20 \%=2$ points, $20-50 \%=3$ points, $50-100 \%=4$ points, and $>100 \%=5$ points. The values for each respective point group were derived from literature values we found for brook trout swimming and leaping capabilities as mentioned before (Kondratieff and Myrick 2006; Adams et al. 2000; Adams et al. 2001; Clarkin et al. 2003; and Dunham et al. 1999). These point totals for each step were added up and divided by the number of steps in each barrier to give a standardized value for the barrier overall. Each overall barrier score was then compared against all other barrier scores within the study area to create a relative difficulty index for the entire study area with a maximum value of one. As the scores approach one, the barrier becomes more severe and therefore difficult for the fish to pass.

\section{Habitat and Fish Sampling}

Reaches were defined as 150 meter sections upstream from a selected point upstream or downstream of a natural barrier. Reaches were measured using a meter tape and every 25 meter increment was marked. At each 25 meter increment, habitat data such as large woody debris and substrate were recorded. Stream wetted width, 
temperature, and $\mathrm{pH}$ were also measured at each site. Fish sampling was conducted using single-pass electrofishing with a Smith-Root LR-24 backpack electrofisher (Smith-Root Inc., Vancouver, WA). Depending on stream size, either one or two electrofishing units were used with at least one netter per electrofisher to ensure similar effort regardless of stream area. Shocking seconds were recorded for each site. All sampling was conducted during summer baseflow conditions. All species were collected with the exception of American eel Anguilla rostrata due to issues with containing them in sample buckets. The total number of eels, however, was counted for each sample reach. Samples were identified to species with counts of all species being recorded.

\section{Data Analysis}

Fish data were analyzed in the context of natural barrier fragmentation using barriers as dividers between fish sampling sites. Comparisons were made between upstream and downstream of barrier sites using t-tests or Mann-Whitney tests when the data were nonparametic. Normality of data was assessed with an Anderson-Darling test for departures from the normal distribution. Comparisons were made with a full range of barrier severities being represented. Sites downstream of barriers were hypothesized to have higher species richness and densities than those sites upstream of barriers.

Therefore, the effects of barriers were tested using one-sided t-tests with the hypothesis being greater richness and densities below natural barriers. Significance levels were set at $\alpha=0.05$ unless otherwise stated. Differences in fish metrics were then analyzed in the context of barrier severity in order to determine a threshold for barrier passability. Pairs

of upstream and downstream sampling sites were tested in groups based upon the level of 
barrier severity that separated them. These groups were classified into four ranges of barrier severity and tested in a similar way. With a potential range of barrier severity between zero and one, the four groups represented the ranges $0-0.3,>0.3-0.4,>0.4-0.6$, and $>0.6-1$. By finding the first barrier group at which the fish sites began to show significant differences, we could assign a threshold value to that level of barrier severity which was actually functional within that system with respect to a particular fish metric.

We then compared habitat variables between the same sampling sites to determine the potential impact of changes in habitat on fish communities. We used two-sided t-tests to compare the water temperature, $\mathrm{pH}$, conductivity, wetted width, large woody debris volume, and percentage of pools between upstream and downstream sites. By comparing habitat variables between sites, we could better understand the impact of the natural barriers themselves on fish communities. In this way, sites with little to no differences in habitat metrics but significant differences in fish metrics could be shown to be more greatly affected by the presence of natural barriers.

We examined the potential effects of barriers on longitudinal profiles of fish assemblages within watersheds. We did this by comparing the presence and densities of both brook and brown trout along the longitudinal range of each stream. In this way, we hoped to identify any role barriers might be playing in spatially structuring the fish communities. We also examined the effects of headwater impoundments on species richness, trout densities, and habitat variables. We did this by simple t-test comparisons between sites with headwater impoundments present versus those sites without these impoundments present. 


\section{Results}

Species richness in sampled sites ranged from 0-15 with a mean richness value of 5.07. Only one site produced no fish and that site was very small (mean wetted-width 1.1 meters) and appeared to have inconsistent flow which would characterize it as marginal fish habitat. Brook trout densities ranged from $0-0.182 \mathrm{fish} / \mathrm{m}^{2}$ with a mean density of $0.0199 \mathrm{fish} / \mathrm{m}^{2}$ while brown trout densities ranged from $0-0.0466 \mathrm{fish} / \mathrm{m}^{2}$ with a mean density of $0.0074 \mathrm{fish} / \mathrm{m}^{2}$. Of the 65 pairs of sites, 36 had brook trout present while 45 had brown trout present. Additionally, 21 pairs of sites contained brown trout but not brook trout, 11 pairs contained brook trout but not brown trout, and 24 pairs contained both. Nine pairs of sites contained neither brook nor brown trout.

\section{Comparison of Sites Upstream versus Downstream of Barriers}

Natural barriers were found in every watershed surveyed, although some contained more than others (Table 2.4). Measurable barriers were present in between 55 of the 65 pairs of sampling sites. The remaining 10 pairs of sites were separated by uninterrupted stream distance and may act as a control for naturally occurring changes in fish communities irrespective of the presence of natural barriers. Richness comparisons between those sites without barriers showed no significant difference $(\mathrm{P}=0.451)$ while those sites with natural barriers showed a significant difference $(\mathrm{P}=0.031)$ (Figure 2.3). However, brook and brown trout densities were not significantly different between nonbarrier sites $(\mathrm{P}=0.628 \& 0.729$ respectively) or barrier sites $(\mathrm{P}=0.961 \& 0.079$ respectively for trout type) (Figures 2.6 and 2.7). 
There were no significant differences in habitat variables for sites separated by non-barriers. Habitat variables measured and tested were $\mathrm{pH}$, conductivity $(\mathrm{uS} / \mathrm{cm})$, water temperature $\left({ }^{\circ} \mathrm{C}\right)$, wetted width $(\mathrm{m})$, large-woody debris volume $\left(\mathrm{m}^{3}\right)$, substrate (numerical average), and proportion of pool habitat (expressed as a fraction of the total stream area sampled). None of these variables were significantly different between sites separated by barriers with the exception of wetted width $(\mathrm{P}=0.041)$ (Figure 2.8). This is expected due to downstream tendency of streams to increase size (Vannote et al. 1980). This difference would not likely contribute significantly to shaping fish communities within these systems since stream size is fairly constant in mainstream branches within the study area and any density difference would be captured since stream area was incorporated into those metrics.

\section{Differences Between Impounded and Non-Impounded Streams}

Fish communities and trout species abundance were influenced by the presence of headwater impoundments. Impoundments were present in 12 of the 16 watersheds surveyed, often located outside of the study area boundaries. For the 12 watersheds with impoundments, 58 sites had significantly higher species richness than 23 sites in streams with no impoundments $(\mathrm{P}<0.001)$ (Figure 2.4). Sites with impoundments also had significantly lower brook trout density than those sites without impoundments present (P $<0.001$ ) (Figures 2.2 and 2.9). There was no significant difference between sites influenced and uninfluenced by impoundment with respect to brown trout density $(\mathrm{P}=$ 0.371). Brook trout were found at 20 out of 58 (34.5\%) impoundment-influenced sites and 18 out of $23(78.3 \%)$ of sites not influenced by impoundments. For the 
impoundment-influenced sites 30 out of $58(51.7 \%)$ had brown trout present while 9 out of $23(39.1 \%)$ sites not influenced by impoundments had brown trout present.

Water quality and habitat were also affected by the presence of headwater impoundments. Sites influenced by impoundments had significantly higher temperature, wetted-width, $\mathrm{pH}$, and conductivity ( $\mathrm{P}<0.001,<0.001,0.036$, and 0.036 respectively) (Figures 2.10 and 2.11). There were no significant differences between influenced and uninfluenced sites for large woody debris volume, mean substrate type, and percentage of pool habitat $(\mathrm{P}=0.749,0.634$, and 0.553 respectively). Significant differences for both $\mathrm{pH}$ and conductivity, however, could be inconsequential because mean values were within brook trout tolerance limits (Raleigh 1982) (mean $\mathrm{pH}=7.5$ for impoundedinfluenced and 7.3 for uninfluenced and mean conductivity $=166 \mathrm{uS} / \mathrm{cm}$ for impoundedinfluenced and $116.1 \mathrm{uS} / \mathrm{cm}$ for uninfluenced).

\section{Defining a Functional Barrier}

One of the objectives of this work was to identify a barrier difficulty level which impacts fish assemblages. After creating a standardized survey method for barrier assessment, we compared fish communities upstream and downstream of barriers throughout the range of difficulty scores. Given no significant differences in brook or brown trout densities between sites regardless of barrier presence or absence, we expected no influence based upon the severity of the barrier. Instead, we relied on species richness to define a "functional" barrier that affects fish communities within our study area. The barriers were assessed using the score categories listed in the previous 
section. Paired sites without fish were not used as these would not provide any information about barrier effects.

Species richness differed significantly between sites upstream and downstream of barriers for the second barrier difficulty group $(>0.3-0.4(\mathrm{P}=0.027)$, and for the fourth level group $(>0.6-1, \mathrm{P}=0.022)$. Significant differences, however, did not occur for the first barrier difficulty group $(0-0.3, \mathrm{P}=0.222)$ or for the third group $(>0.4-0.6, \mathrm{P}=$ $0.137)$, but may be influenced by a smaller sample size $(n=9)$ for the third group. This indicates that the threshold value for a functional difference in species richness is in the range of $0.3-0.4$ of barrier scores (Table 2.1). These same tests gave no significant results for brook trout density regardless of the barrier severity group. However, brown trout density showed a significant difference at the highest barrier difficult level from $>0.6-1(\mathrm{P}=0.006)$. This indicates that at the most severe barrier difficulties, brown trout densities may be functionally affected by natural barrier presence. Habitat values broken down by these barrier groups also showed no significant differences between upstream and downstream sites (Table 2.2).

\section{Evaluation of Longitudinal Richness Patterns}

We estimated differences in species richness between upstream and downstream barrier sites, and expected higher species richness downstream of barriers. This allowed evaluation of streams within the context of increasing richness as you move downstream into larger habitat zones (Vannote et al. 1980). Surprisingly, 16 out of the $65(24.6 \%)$ pairs of sampled sites actually had higher species richness upstream of the barrier than downstream. Of these 16 sites, $13(81.3 \%)$ pairs of sites had a headwater impoundment 
located somewhere within the watershed. Comparison of mean species richness between streams with and without headwater impoundments across a longitudinal range of sites from mouth to headwater showed a higher mean richness for impounded streams. Also, the pattern of decreasing richness as you move upstream into the headwaters was absent in the sites with impoundments (Figure 2.5).

\section{Discussion}

\section{Extent of Natural Barrier Fragmentation}

Natural barriers have been assumed impassable to fish and have been treated as such in previous research (McCart and Bain 1974; Roghair and Dolloff 2005; Gresswell and Hendricks 2007). Natural barriers have also been previously defined mathematically using hydrologic conditions of the stream and geometric structure of the barrier (Powers and Orsburn 1985). This study sought to examine natural barriers to provide a rigorous, standardized approach to passability without detailed mathematical methods and reliance on constant flow conditions. This would potentially allow broad application and easier implementation. To do this, we used coarse fish community metrics to assess differences among sampled sites with barriers of differing passability scores. The extent of these sites covered 16 watersheds and approximately 96.3 stream kilometers. Every watershed sampled contained fish and suitable fish habitat so the relative importance of barriers could be equally examined. The amount of natural obstructions and barriers occurring in streams is likely higher than the amount we found at any given time since our sampling strategy was synoptic and could not account for barriers which were temporary due to flow conditions. 
I found natural barriers to have differing effects on fish communities depending on both their ranked severity and the fish metric being tested. While barriers seemed to play a role in helping to define species richness throughout a stream reach, they showed little if any effect on brook and brown trout densities. This could be attributable to swimming performance of fish species, as brook and brown trout have been described as some of the strongest swimming freshwater fishes in the U.S. along with other salmonids (Peake et al. 1997; Coffman 2005; Adams et al. 2000). Barriers may also affect fish communities differently based on spatial location within the stream network. Barriers could potentially isolate native brook trout populations in headwater areas by preventing invasion of nonnative species based upon network topology (Fausch et al. 2009). Other factors such as habitat and competition could also be more greatly affecting certain species distributions more so than the presence of natural barriers.

\section{Role of Other Factors Defining Fish Communities}

Fish communities within the study area were variably affected by the presence and severity of natural barriers. Other factors not measured during this study, however, may have also influenced fish community distributions. While there were barrier effects at the community level when comparing species richness, the composition of these richness values was not examined. This means that within a given species richness number, there could be several different species of fish which had diverse habitat preferences, feeding habits, and/or reproductive strategies. Therefore, habitat variables such as temperature, substrate, and others could be just as important in defining suitable areas for these species as the presence of barriers. Even with the findings of no 
significant habitat differences between sites separated by barriers, there cannot be absolute certainty that the barriers are exerting a greater effect on the fish communities than some other environmental variable(s). For brook trout densities, habitat is likely a more important factor than the presence of natural barriers since we found no significant effect of barriers but we found a very dramatic reduction in brook trout density in sites with water temperature above $21^{\circ} \mathrm{C}$ (Figure 2.12). However, brown trout densities showed less dramatic decreases with increasing temperatures although they also showed temperature-dependent patterns of density (Figure 2.13). This indicates that there are specific thermal ranges which brook and brown trout prefer within this study area. This is likely due to increased growth and decreased mortality within certain optimal temperature ranges for both species (McCormick et al. 1972; Wehrly et al. 2007).

Impoundments and fish introductions likely influence the distributions of fishes throughout the study area. The effects of impoundments on stream fish communities have been previously documented (Herbert and Gelwick 2003; Guenther and Spacie 2006) and seem to play an important role in this study. There were significant differences in habitat between streams influenced and uninfluenced by headwater impoundments. This could affect the distribution of fishes within those streams more so than natural barriers. Also, artificial inflation of species richness could occur in sites downstream of headwater impoundments because species could escape impoundments during high flows. This may explain the occurrence of largemouth bass Micropterus salmoides and golden shiner Notemigonus crysoleucas in some headwater sites. Fish distributions within our study streams may also be influenced by angler-induced transfer 
of fishes. Anglers often move game and nongame species through intentional introductions or non-intentional bait bucket introductions.

Another factor worth consideration is the presence of artificial barriers in the form of road culverts and other structures. Since the study area was historically settled for farmland, many of the streams appeared to show signs of previous human influence. Human-created structures such as stone walls and concrete slabs were present in and around some streams with little to no measurable impact. However, the presence of these structures near studied streams indicates the likelihood of these structures occurring throughout the area with high frequencies and with unknown impacts on stream connectivity. Road density was high in portions of the study area which resulted in several stream-road crossings being evaluated for fish passage. Only 7 out of the 65 paired sampling sites had a road culvert in between them and showed no significant differences in any fish or habitat metric tested.

A final issue to address is the presence of multiple natural barriers between sampling sites. When this occurred, we used the barrier with the highest difficulty score which would give a conservative estimate of the passability restrictions imposed by the natural barriers. However, it may be possible that consecutive barriers could act in an additive fashion to decrease connectivity more so than one larger, more difficult barrier. In this way, headwater streams with high frequencies of natural barrier occurrence may act as a strong deterrent to invading species due to the difficulty in traveling into the headwaters. From a trout perspective, this could explain the relative occurrence of brown trout in the lower reaches of streams and brook trout in the uppermost headwater areas. 


\section{Limitations and Suggestions for Future Study}

There are some limitations of this study as they pertain to conclusions drawn.

First, the scale at which we examined differences in fish communities was mostly

confined to the reach scale contained between stream segments. Since our sampling sites covered 150 meters of stream, we did not intensively sample any one microhabitat. This provided useful metrics at a coarse level with which we could make initial determinations about the permeability of natural barriers. However, to completely ascertain the effects of natural barriers within this system, a more localized scale with more concentrated sampling effort would have likely been effective. Analysis done at the population or even individual level could then provide more exact details on fishes' ability to move beyond natural barriers. Increased sampling intensity directly upstream and downstream of barriers could also give a more complete picture of the fish community and account for species that may have had low capture probabilities during our sampling.

Another limitation of this work is the assessment of what is and is not a barrier to fish movement. We attempted to standardize this decision with our protocols but realize that some barriers may only be temporary following channel alterations and flood events. Also, the permeability of barriers is likely variable depending on flow conditions which may offer fishes an alternative passage route. This variability is due to environmental conditions which are outside the scope of our control and would likely affect any other similar study. Although the barrier scoring groups were defined by literature-derived values, a different approach could have been used to classify both the barriers passability index and the groups assigned for passability differences. First, the scoring system used 
the two meter threshold as the cutoff for resident salmonid passability and was therefore biased towards scoring larger barriers as more difficult. This could be done using another method such as a rank-order process to determine weights of barrier step difficulty (Malczewski et al. 1999). Additionally, instead of defining barrier passability groups based upon natural breaks in the score data, a method using other variables or patterns in the data to break up the continuum could have been used. Depending on the way these groups are classified, biological response to barrier may be more or less difficult to detect.

Future work may build upon this initial examination of natural barrier effect on fish communities by going into greater detail or perhaps using systems which lack natural barriers for comparison. Mark-recapture studies using areas upstream and downstream of barriers could provide more detailed passage information at a more localized scale. Also, genetic techniques may provide clues as to which barriers are being traversed by certain individuals or if natural barriers may act to form genetically distinct populations of the same species within a stream network. In spite of these limitations, this research still provides a useful methodology and pragmatic approach to questions of natural barrier effects on fish communities which have previously been seldom explored.

\section{Literature Cited}

Adams, S.B., C.A. Frissell, and B.E. Rieman. 2001. Geography of invasion in mountain streams: consequences of headwater lake fish introductions. Ecosystems 4: 296307.

Adams, S.B., C.A. Frissell, and B.E. Rieman. 2000. Movements of nonnative brook trout in relation to stream channel slope. Transactions of the American Fisheries Society 129: 623-638. 
Bozek, M. A., and W. A. Hubert. 1992. Segregation of resident trout in streams as predicted by three habitat dimensions. Canadian Journal of Zoology 70: 886-890.

Brown, S.K., K.R. Buja, S.H. Jury, M.E. Monaco, and A. Banner. 2000. Habitat suitability index models for eight fish and invertebrate species in Casco and Sheepscot Bays, Maine. North American Journal of Fisheries Management 20: 408-435.

Clarkin, K., A. Connor, M.J. Furniss, B. Gubernick, M. Love, K Moynan, and S.W. Musser. 2003. National inventory and assessment procedure for identifying barriers to aquatic organism passage at road-stream crossings. U.S. Forest Service, San Dimas, CA.

Coffman, J.S. 2005. Evaluation of a predictive model for upstream fish passage through culverts. James Madison University.

Conservation Strategy Work Group - Eastern Brook Trout Joint Venture. 2005. Conserving the eastern brook trout: an overview of status, threats, and trends. http://www.state.nj.us/dep/fgw/pdf/tic_cons_eastern_bkt.pdf

Dunham, J. B., M. M. Peacock, B. E. Rieman, R. E. Schroeter, and G. L. Vinyard. 1999. Local and geographic variability in the distribution of stream-living Lahontan cutthroat trout. Transactions of the American Fisheries Society 128: 875-889.

ESRI 2011. ArcGIS Desktop: Release 10. Redlands, CA: Environmental Systems Research Institute.

Epstein, J. B. Geology of Delaware Water Gap National Recreation Area, New JerseyPennsylvania. Excursions in Geology and History: Field Trips in the Middle Atlantic States. Boulder, CO: Geological Society of America, 2006. 47-64. Print.

Fagan, W. F. 2002. Connectivity, fragmentation, and extinction risk in dendritic metapopulations. Ecology 83: 3243-3249.

Fausch, K. D., B. E. Rieman, J. B. Dunham, M. K. Young, and D. P. Peterson. 2009. Invasion versus isolation: trade-offs in managing native salmonids with barriers to upstream movement. Conservation Biology 23: 859-870.

Fausch, K. D. and M. K. Young. 1995. Evolutionary significant units and movement of resident stream fishes: a cautionary tale. Pages 360-370 in J. L. Nielsen, editor. Evolution and the aquatic system: defining unique units in population conservation. American Fisheries Society, Symposium 17, Bethesda, Maryland.

Fausch, K.D. and R.J. White. 1981. Competition between brook trout (Salvelinus fontinalis) and brown trout (Salmo trutta) in a Michigan stream. Canadian Journal of Fisheries and Aquatic Sciences 38: 1220-1227.

Gillenwater, D., T. Granata, and U. Zika. 2006. GIS-based modeling of spawning habitat suitability for walleye in the Sandusky River, Ohio, and implications for dam removal and river restoration. Ecological Engineering 28: 311-323.

Gowan, C. and K.D. Fausch. 1996. Mobile brook trout in two high-elevation Colorado streams: re-evaluating the concept of restricted movement. Canadian Journal of Fisheries and Aquatic Sciences 53: 1370-1381.

Gresswell, R. E., and S. R. Hendricks. 2007. Population-scale movement of coastal cutthroat trout in a naturally isolated stream network. Transactions of the American Fisheries Society 136: 238-253. 
Guenther, C. B., and A. Spacie. 2006. Changes in fish assemblage structure upstream of impoundments within the upper Wabash River basin, Indiana. Transactions of the American Fisheries Society 135: 570-583.

Herbert, M. E., and F. P. Gelwick. 2003. Spatial variation of headwater fish assemblages explained by hydrologic variability and upstream effects of impoundment. Copeia 2003: 273-284.

Hudy, M., T.M. Thieling, N. Gillespie, and E.P. Smith. 2008. Distribution, status, and land use characteristics of subwatersheds within the native range of brook trout in the eastern United States. North American Journal of Fisheries Management 28: 1069-1085.

Isaak, D. J., R. F. Thurow, B. E. Rieman, and J. B. Dunham. 2007. Chinook salmon use of spawning patches: relative roles of habitat quality, size, and connectivity. Ecological Applications 17: 352-364.

Kanda, N., R.F. Leary, and F.W. Allendorf. 2002. Evidence of introgressive hybridization between bull trout and brook trout. Transactions of the American Fisheries Society 131: 772-782.

Kondratieff, M.C. and C.A. Myrick. 2006. How high can brook trout jump? A laboratory evaluation of brook trout jumping performance. Transactions of the American Fisheries Society 135: 361-370.

Larson, G.L. and S.E. Moore. 1985. Encroachment of exotic rainbow trout into stream populations of native brook trout in the southern Appalachian mountains. Transactions of the American Fisheries Society 114: 195-203.

Mabin, M.C.G. 2000. In search of Australia's highest waterfalls. Australian Geographical Studies 38: 85-90.

Malczewski, J. 1999. GIS and multicriteria decision analysis. John Wiley, New York

Marion, J.L, and D.N. Cole. 1996. Spatial and temporal variation in soil and vegetation impacts on campsites. Ecological Applications 6: 520-530.

Mayden, R. L. 1987. Historical ecology and North American highland fishes: A research program in community ecology, p. 210-222. In: W. J. Matthews and D. C. Heins (eds.). Community and Evolutionary Ecology of North American Stream Fishes. University of Oklahoma Press, Norman.

McCart, P. and H Bain. 1974. An isolated population of arctic char (Salvelinus alpinus) inhabiting a warm mineral spring above a waterfall at Cache creek, Northwest Territories. Journal of the Fisheries Research Board of Canada 31: 1408-1414.

McCormick, J.H., K.E.F. Hokanson, and B.R. Jones. 1972. Effects of temperature on growth and survival of young brook trout, Salvelinus fontinalis. Journal of the Fisheries Research Board of Canada 29: 1107-1112.

NCDC: National Climatic Data Center (NCDC) . 29 Nov. 2011. Web. 20 Nov. 2011. <http://www.ncdc.noaa.gov/oa/ncdc.html>.

NRCS National Water and Climate Center - Climate Products - PRISM. NRCS National Water and Climate Center. Web. 18 Nov. 2011. <http://www.wcc.nrcs.usda.gov/climate/prism.html >.

Nelson, R.L., W.S. Platts, D.P. Larsen, and S.E. Jensen. 1992. Trout distribution and habitat in relation to geology and geomorphology in the North Fork Humboldt River drainage, northeastern Nevada. Transactions of the American Fisheries Society 121: 405-426. 
Page, L.M. and B.M. Burr. 1991. A field guide to freshwater fishes of North America north of Mexico. Houghton Mifflin Company, Boston. $432 \mathrm{p}$.

Peake, S., R.S. McKinley, and D.A. Scruton. 1997. Swimming performance of various freshwater Newfoundland salmonids relative to habitat selection and fishway design. Journal of Fish Biology 51: 710-723.

Peterson, D.P. and K.D. Fausch. 2003. Upstream movement by nonnative brook trout (Salvelinus fontinalis) promotes invasion of native cutthroat trout (Oncorhynchus clarki) habitat. Canadian Journal of Fisheries and Aquatic Sciences 60: 15021516.

Petty, J.T., and G.D. Grossman. 2004. Resticted movement by mottled sculpin (pisces: cottidae) in a southern Appalachian stream. Freshwater Biology 49: 631-645.

Petty, J. T., P. J. Lamothe, and P. M. Mazik. 2005. Spatial and seasonal dynamics of brook trout populations inhabiting a central Appalachian watershed. Transactions of the American Fisheries Society 134: 572-587.

Powers, P.D. and J.F. Orsburn. 1985. Analysis of barriers to upstream fish migration: an investigation of the physical and biological conditions affecting fish passage success at culverts and waterfalls. Final Project Report for Bonneville Power Administration. Albrook hydraulics laboratory - Washington State University.

Raleigh, R. F. 1982. Habitat suitability index models: Brook trout. U.S. Dept. Int., Fish Wildl. Serv. FWS/OBS-82/10.24. 42 pp.

Roghair, C. N., and C. A. Dolloff. 2005. Brook trout movement during and after recolonization of a naturally defaunated stream reach. North American Journal of Fisheries Management 25: 785-790.

Strange, R.J. and J.W. Habera. 1998. No net loss of brook trout distribution in areas of sympatry with rainbow trout in Tennessee streams. Transactions of the American Fisheries Society 127: 434-440.

Townsend, C.R. and T.A. Crowl. 1991. Fragmented population structure in a native New Zealand fish: an effect of introduced brown trout? Oikos 61: 347-354.

Vannote, R.L., G.W. Minshall, K.W. Cummins, J.R. Sedell, and C.E. Cushing. 1980. The river continuum concept. Canadian Journal of Fisheries and Aquatic Sciences 37: $130-137$.

Ward, J.V. and J.A. Stanford. 1983. The serial discontinuity concept of lotic ecosystems. Pages 29-43 in T.D. Fontaine III and S.M. Bartell, editors. Dynamics of lotic ecosystems. Ann Arbor Science, Ann Arbor, Michigan.

Wehrly, K.E., L. Wang, and M. Mitro. 2007. Field-based estimates of thermal tolerance limits for trout: incorporating exposure time and temperature fluctuation. Transactions of the American Fisheries Society 136: 365-374. 
Table 2.1: Summary of tests for differences in biological endpoints when comparing upstream and downstream sampling sites across the range of barrier severity levels. Species richness showed a significant difference once the 0.3 threshold was passed while trout densities were unaffected at any level except brown trout at the highest barrier difficulty level.

\begin{tabular}{lcccc}
\hline $\begin{array}{c}\text { Biological } \\
\text { Endpoint }\end{array}$ & $\begin{array}{c}\text { Barrier } \\
\text { Difficulty } \\
\text { Level Group }\end{array}$ & $\begin{array}{c}\text { Sample } \\
\text { Size, } \mathbf{N}\end{array}$ & $\begin{array}{c}\text { Mean } \\
\text { Difference }\end{array}$ & P-Value \\
\hline Species richness & $0-0.3$ & 19 & 0.5263 & 0.222 \\
& $>0.3-0.4$ & 13 & 1.1538 & 0.027 \\
& $>0.4-0.6$ & 9 & 0.7777 & 0.137 \\
Brook trout & $>0.6-1$ & 21 & 1.7619 & 0.022 \\
density & & & & \\
& $0-.0 .3$ & 10 & -62.66 & 0.343 \\
& $>0.3-0.4$ & 10 & 12.67 & 0.414 \\
Brown trout & $>0.4-0.6$ & 4 & 56.67 & 0.281 \\
density & $>0.6-1$ & 11 & -21.82 & 0.597 \\
& & & & \\
& $0-.0 .3$ & 16 & 9.58 & 0.101 \\
& $>0.3-0.4$ & 9 & 9.63 & 0.367 \\
& $>0.4-0.6$ & 5 & -2.66 & 0.536 \\
& $>0.6-1$ & 15 & 25.33 & 0.006 \\
\hline
\end{tabular}

Table 2.2: Summary of tests for habitat differences comparing upstream and downstream sampling sites across the range of barrier severity levels. There were no significant differences in measured habitat variables across all barrier difficulty levels with the exception of wetted width $(\mathrm{P}=0.041)(\mathrm{n}=65)$.

\begin{tabular}{lcc}
\hline $\begin{array}{c}\text { Habitat } \\
\text { Variables }\end{array}$ & $\begin{array}{c}\text { Mean } \\
\text { Difference }\end{array}$ & P-Value \\
\hline pH & 0.029 & 0.646 \\
Conductivity & -4.71 & 0.811 \\
Temperature & -0.349 & 0.464 \\
Wetted width & 0.787 & 0.041 \\
LWD volume & 0.0327 & 0.961 \\
Mean substrate & -0.0161 & 0.814 \\
$\%$ Pool & 0.0093 & 0.565 \\
\hline
\end{tabular}


Table 2.3: Summary data for watersheds sampled. Watersheds were randomly selected within strata for elevation, stream order, geology and stream slope. Geology was broken down categorically based on area of each type of formation within a watershed. Examples of each geology type: Soft $=$ shales, limestone Medium $=$ siltstone, claystone Hard $=$ quartzite, sandstone. Stream slopes were broken down by the following categories: Low $=0-12 \%$ Medium $=12-20 \%$ High $=>20 \%$

\begin{tabular}{|c|c|c|c|c|c|c|c|}
\hline Name & $\begin{array}{c}\text { Watershed } \\
\text { Area } \\
\text { (hectares) }\end{array}$ & $\begin{array}{c}\text { Mean } \\
\text { Elevation } \\
\text { (m) }\end{array}$ & $\begin{array}{l}\text { Elevation } \\
\text { Range }\end{array}$ & $\begin{array}{c}\text { Stream } \\
\text { Order } \\
\text { (Strahler) }\end{array}$ & $\begin{array}{c}\text { Stream } \\
\text { Length } \\
(\mathbf{k m})\end{array}$ & Geology & $\begin{array}{c}\text { Stream } \\
\text { Slope }\end{array}$ \\
\hline Raymondskill & 6191.7 & 244.3 & 192 & 3 & 6.7 & Medium & High \\
\hline White Brook & 546.1 & 195.6 & 130 & 1 & 2.2 & Medium & Low \\
\hline Adams & 1950.7 & 247.9 & 201 & 2 & 6.6 & Medium & Medium \\
\hline Conashaugh & 538.3 & 239.4 & 186 & 1 & 3 & Medium & High \\
\hline Dingmans & 4404.9 & 219.7 & 208 & 3 & 11.5 & Medium & Medium \\
\hline Hornbecks & 2372.6 & 206.8 & 173 & 3 & 9 & Medium & High \\
\hline Toms & 2414.2 & 227.8 & 228 & 3 & 4.8 & Medium & Medium \\
\hline Mill & 1056.4 & 232.9 & 227 & 2 & 4.4 & Medium & Medium \\
\hline Alicias & 138.9 & 225.1 & 170 & 1 & 2 & Medium & High \\
\hline $\begin{array}{l}\text { Heller } \\
\text { Randall }\end{array}$ & 172.2 & 235.8 & 185 & 1 & 2.7 & Medium & Medium \\
\hline VanCampens & 587.3 & 206.2 & 171 & 2 & 3.8 & Medium & Medium \\
\hline VanCampens & 2379.6 & 290.8 & 371 & 2 & 20.3 & Medium & Medium \\
\hline Dunnfield & 1004.2 & 363.7 & 398 & 1 & 6.4 & Medium/Hard & High \\
\hline Caledonia & 256.1 & 296.2 & 351 & 1 & 3 & Medium & Medium \\
\hline Spackmans & 294.9 & 226.2 & 173 & 1 & 2.1 & Medium & High \\
\hline Flat Brook Tributary & $\mathrm{N} / \mathrm{A}$ & $\mathrm{N} / \mathrm{A}$ & 251 & 1 & 1.9 & Medium/Hard & High \\
\hline
\end{tabular}


Table 2.4: Summary of watersheds sampled with natural barrier occurrence shown as number of barriers and as barrier density, or number of barrier per stream kilometer.

\begin{tabular}{lcccc}
\hline \multicolumn{1}{c}{ Watershed } & $\begin{array}{c}\text { Number of } \\
\text { Barriers }\end{array}$ & Stream $\mathbf{~ k m}$ & Barriers/km & State \\
\hline Adams & 31 & 6.6 & 4.70 & PA \\
Alicias & 12 & 2 & 6.00 & PA \\
Caledonia & 9 & 3 & 3.00 & PA \\
Conashaugh & 16 & 3 & 5.33 & PA \\
Dingmans & 14 & 11.5 & 1.22 & PA \\
Dunnfield & 23 & 6.4 & 3.59 & NJ \\
FBT (DC) & 32 & 1.3 & 24.62 & NJ \\
FBT (SP5) & 12 & 1.3 & 9.23 & NJ \\
Heller & 24 & 2.7 & 8.89 & PA \\
Hornbecks & 21 & 9 & 2.33 & PA \\
Mill & 22 & 4.4 & 5.00 & PA \\
Randall Vancampens & 22 & 3.8 & 5.79 & PA \\
Raymondskill & 20 & 6.7 & 2.99 & PA \\
Spackmans & 15 & 2.1 & 7.14 & PA \\
Toms & 28 & 11.3 & 2.48 & PA \\
Vancampens & 50 & 20.3 & 2.46 & NJ \\
White & 4 & 2.2 & 1.82 & NJ \\
\hline
\end{tabular}




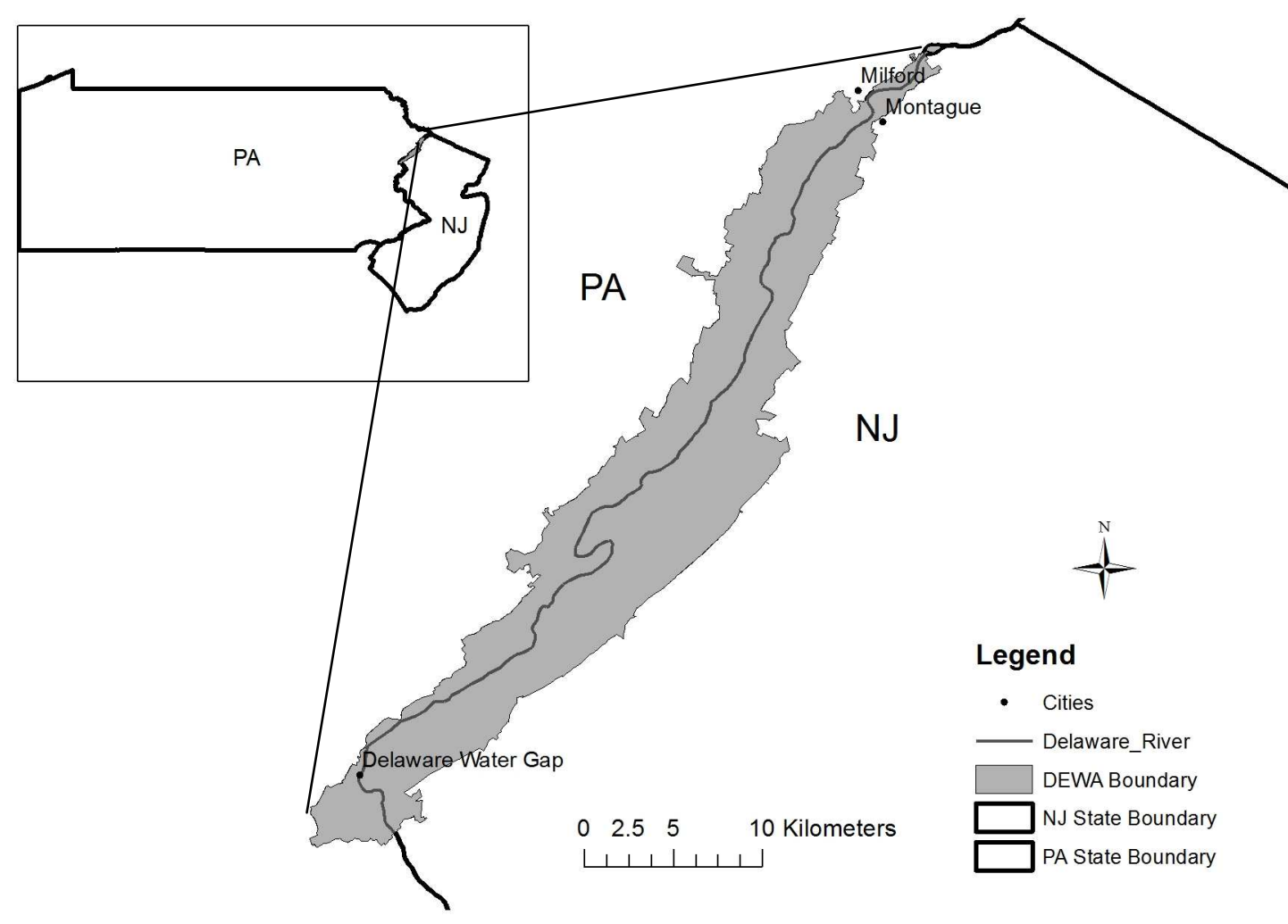

Figure 2.1: Delaware Water Gap National Recreation Area in relation to surrounding cities and states.

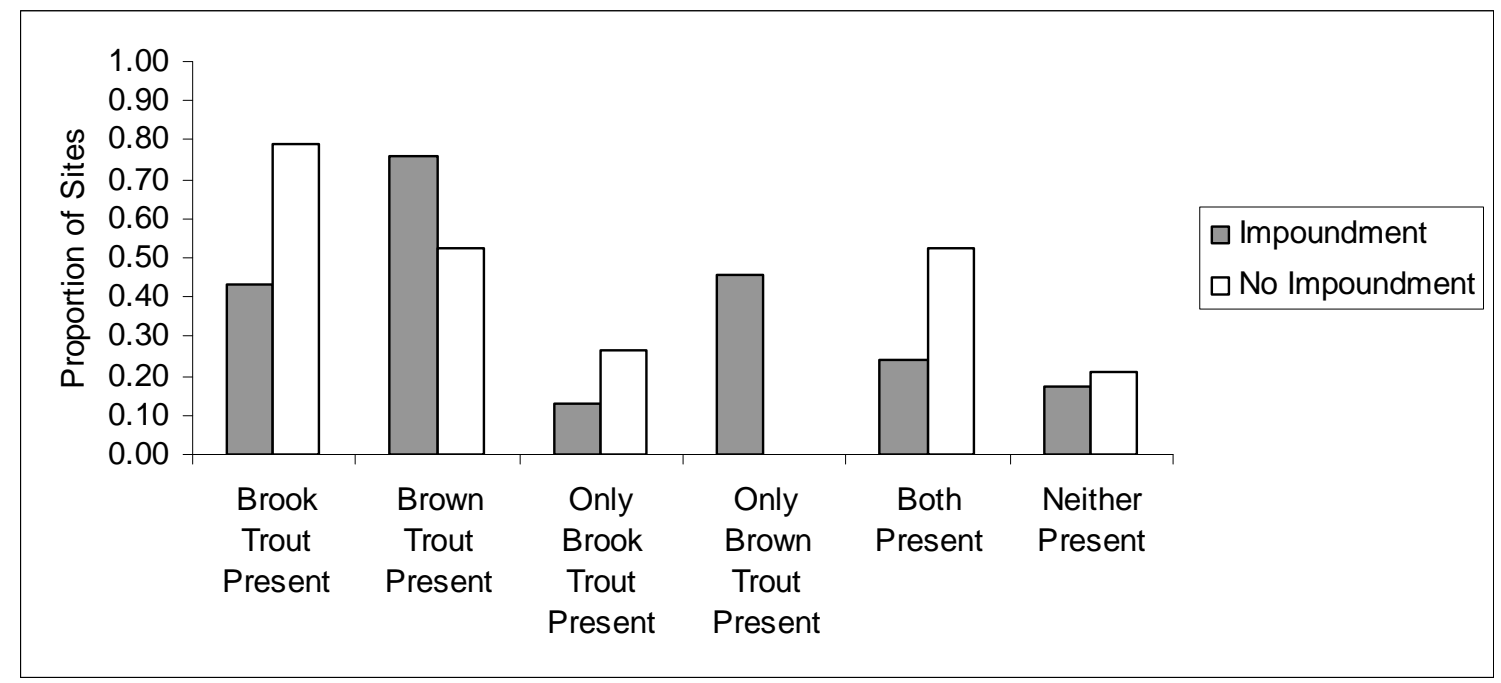

Figure 2.2: Presence of brook trout and brown trout in impounded and unimpounded headwater streams of the Delaware Water Gap National Recreation Area. 


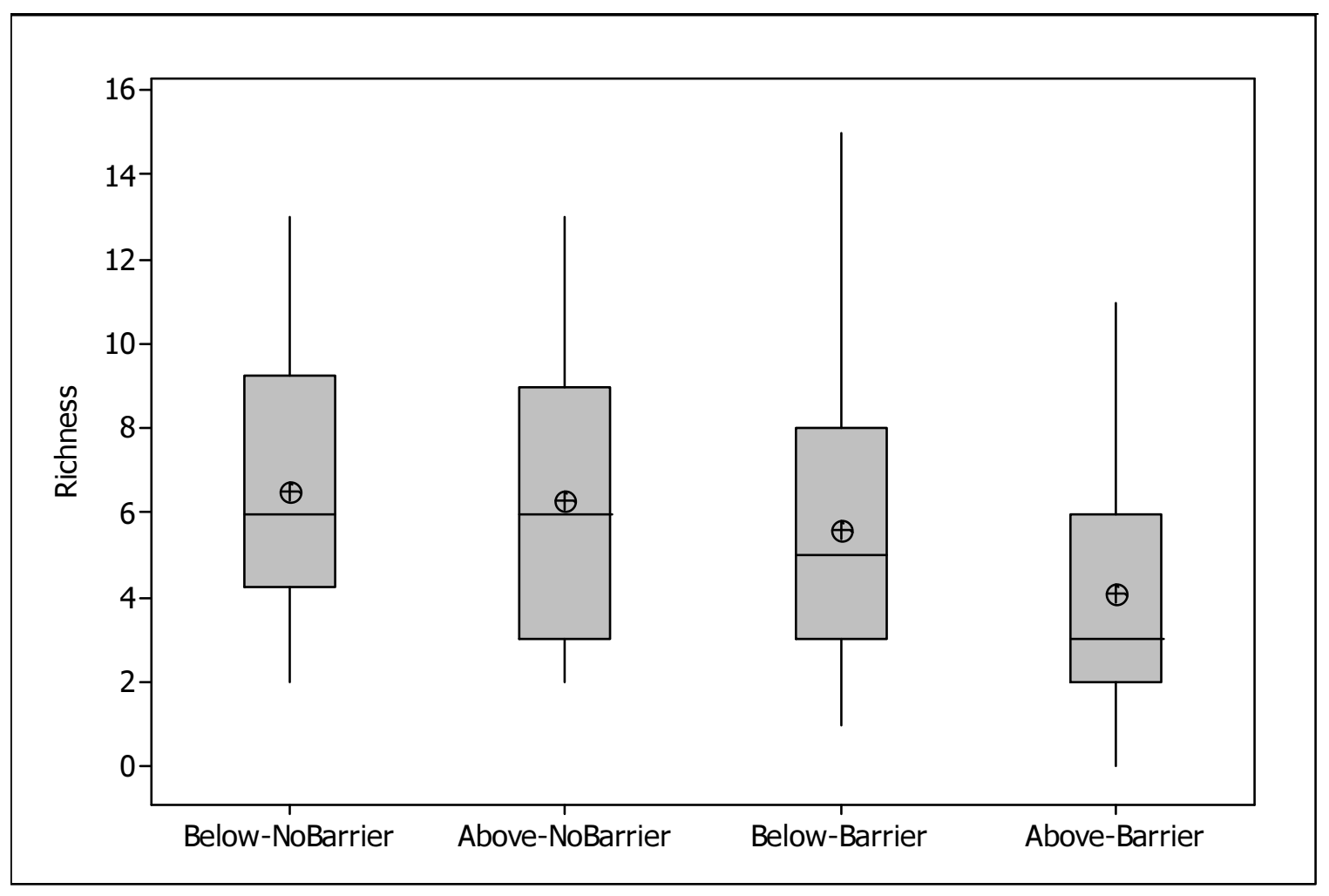

Figure 2.3: Sampled species richness differences between fish sampling sites with no functional natural barrier and sites with a functional natural barrier. Richness between sites below and above a barrier showed a significant difference $(\mathrm{P}=0.0312)$ while those with no barrier showed no significant difference $(\mathrm{P}=0.451)$. Boxes represent interquartile range with a median bar while the bull's-eye represents the mean value for each group. Whiskers represent the full data range with minimum and maximum values. 


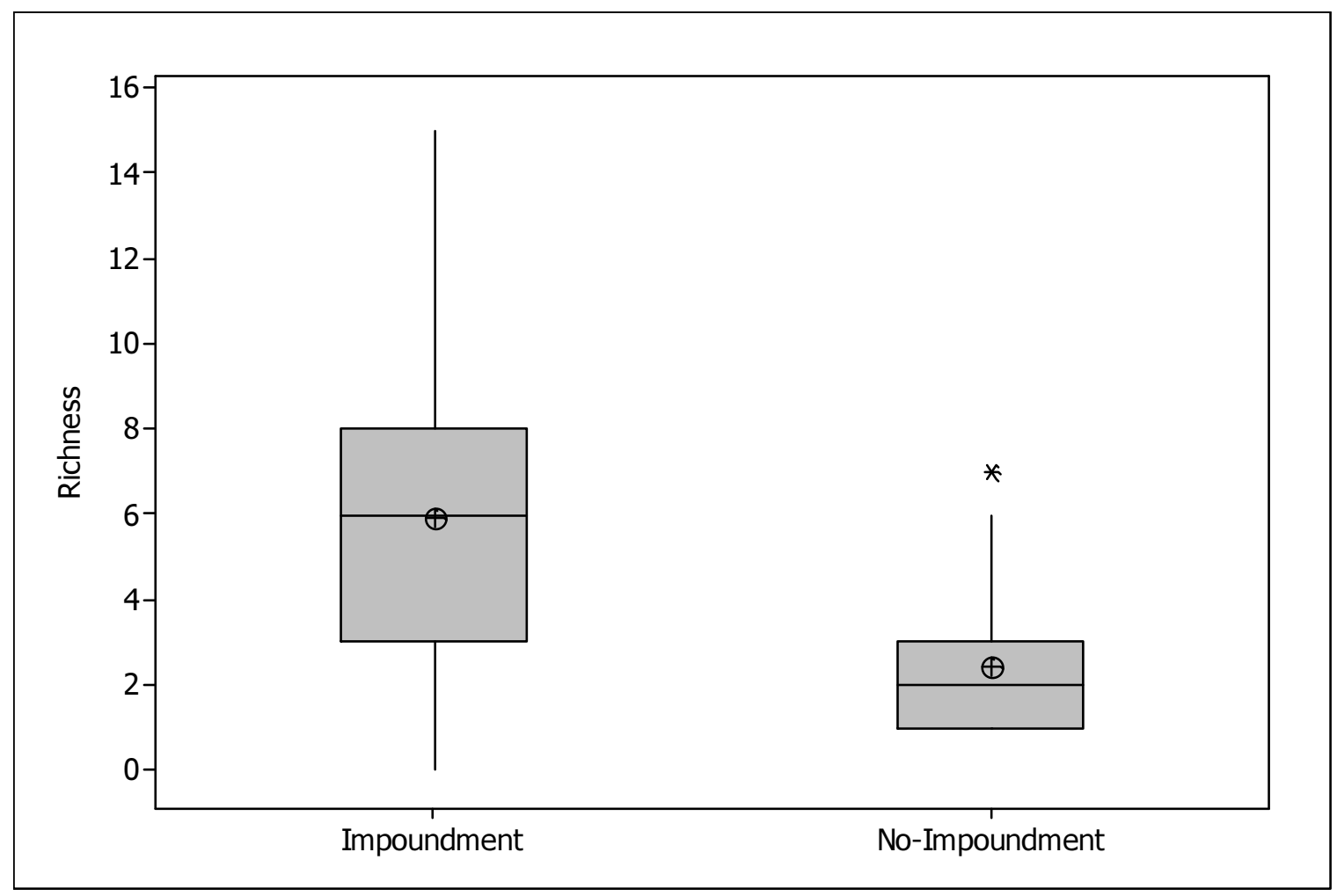

Figure 2.4: Sampled species richness differences between sites with a headwater impoundment present and sites with no impoundment present showed a significant difference $(\mathrm{P}<0.001)$. Boxes represent interquartile range with a median bar while the bull's-eye represents the mean value for each group. Whiskers represent the full data range with minimum and maximum values. 


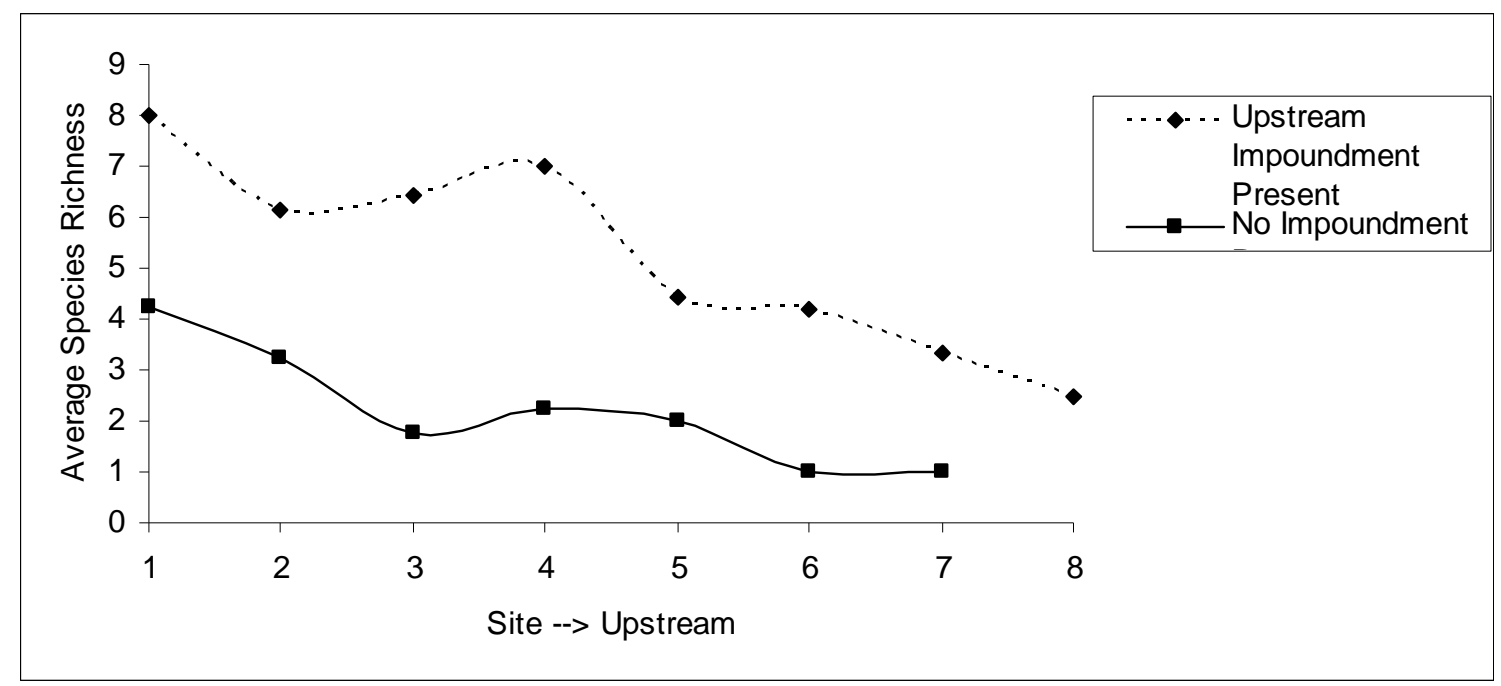

Figure 2.5: Patterns of average sampled species richness in sites both affected and unaffected by upstream impoundment presence. Notice an unusual pattern in the sites with upstream impoundments present as you move upstream. Observed richness actually increases for a site or two then continues its decline as you move into the headwaters. This could provide evidence for an artificial inflation of species richness values in streams influenced by headwater impoundments depending on where fishes that are flushed downstream end up colonizing or at the very least are detected by our sampling. 


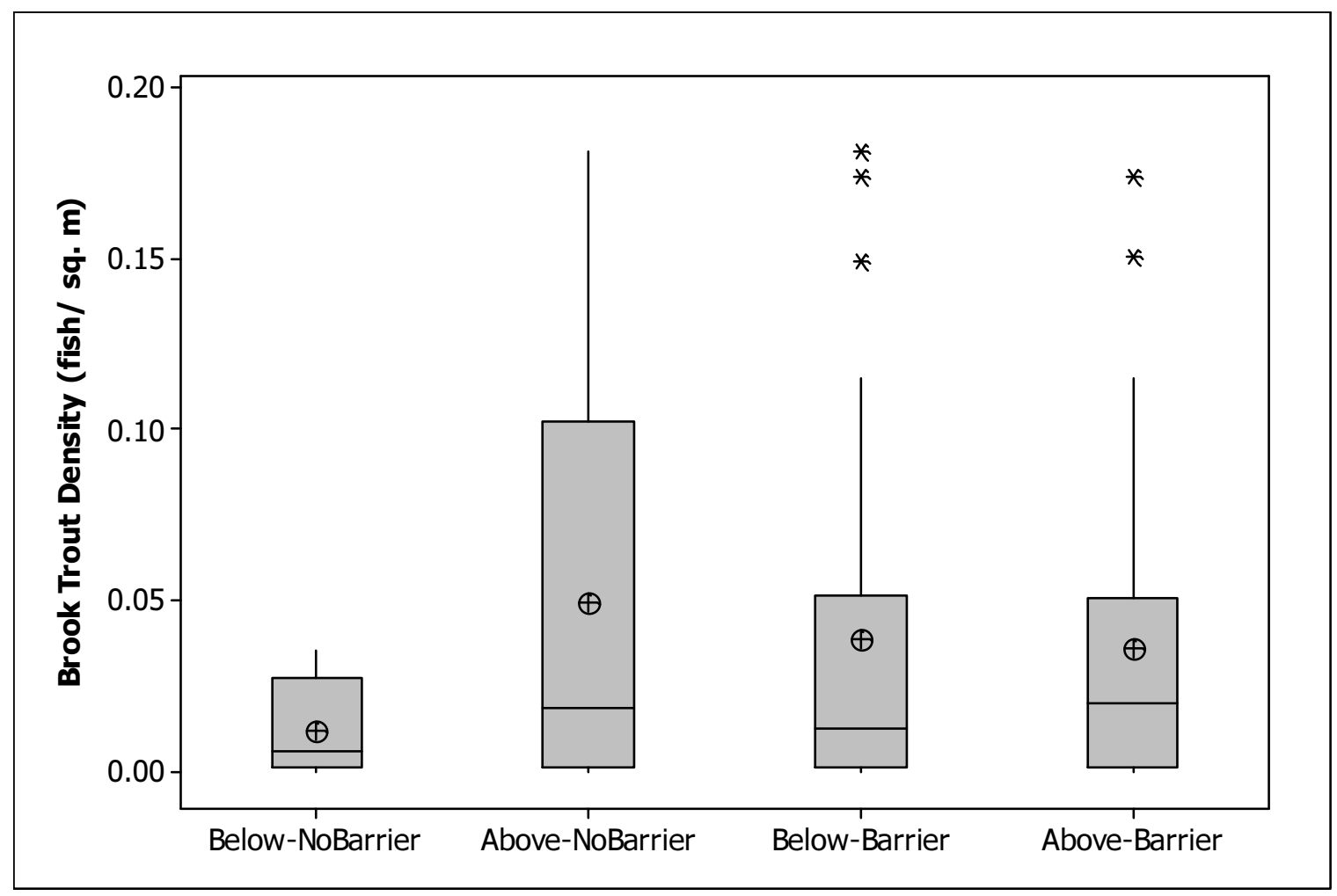

Figure 2.6: Sampled brook trout density differences between fish sampling sites with no functional natural barrier and sites with a functional natural barrier. Density between sites below and above a barrier and a non-barrier showed no significant differences $(\mathrm{P}=0.961$ and 0.628 respectively). Boxes represent interquartile range with a median bar while the bull's-eye represents the mean value for each group. Whiskers represent the full data range with minimum and maximum values. 


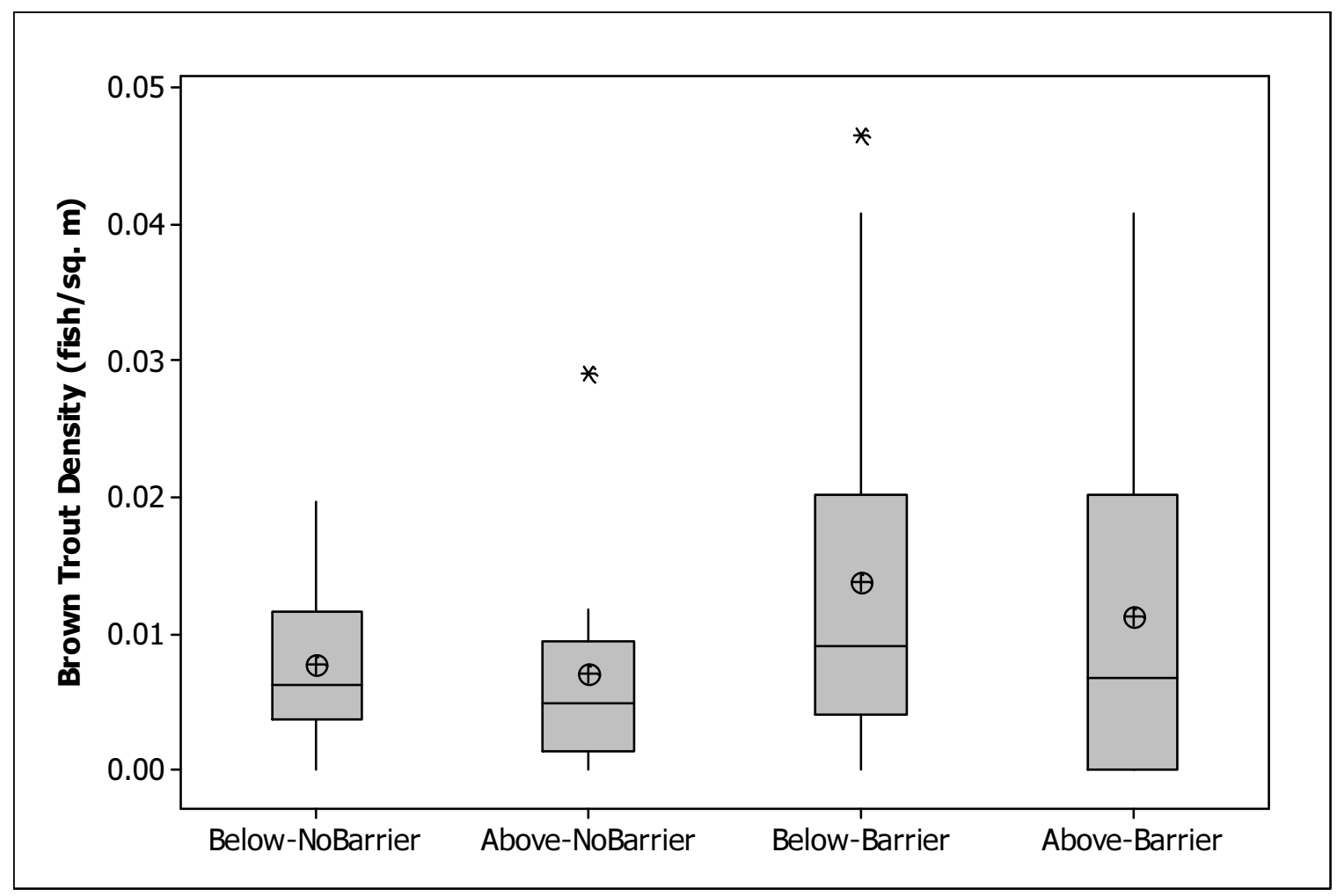

Figure 2.7: Sampled brown trout density differences between fish sampling sites with no functional natural barrier and sites with a functional natural barrier. Density between sites below and above a barrier and a non-barrier showed no significant differences $(\mathrm{P}=0.079$ and 0.729 respectively). Boxes represent interquartile range with a median bar while the bull's-eye represents the mean value for each group. Whiskers represent the full data range with minimum and maximum values. 


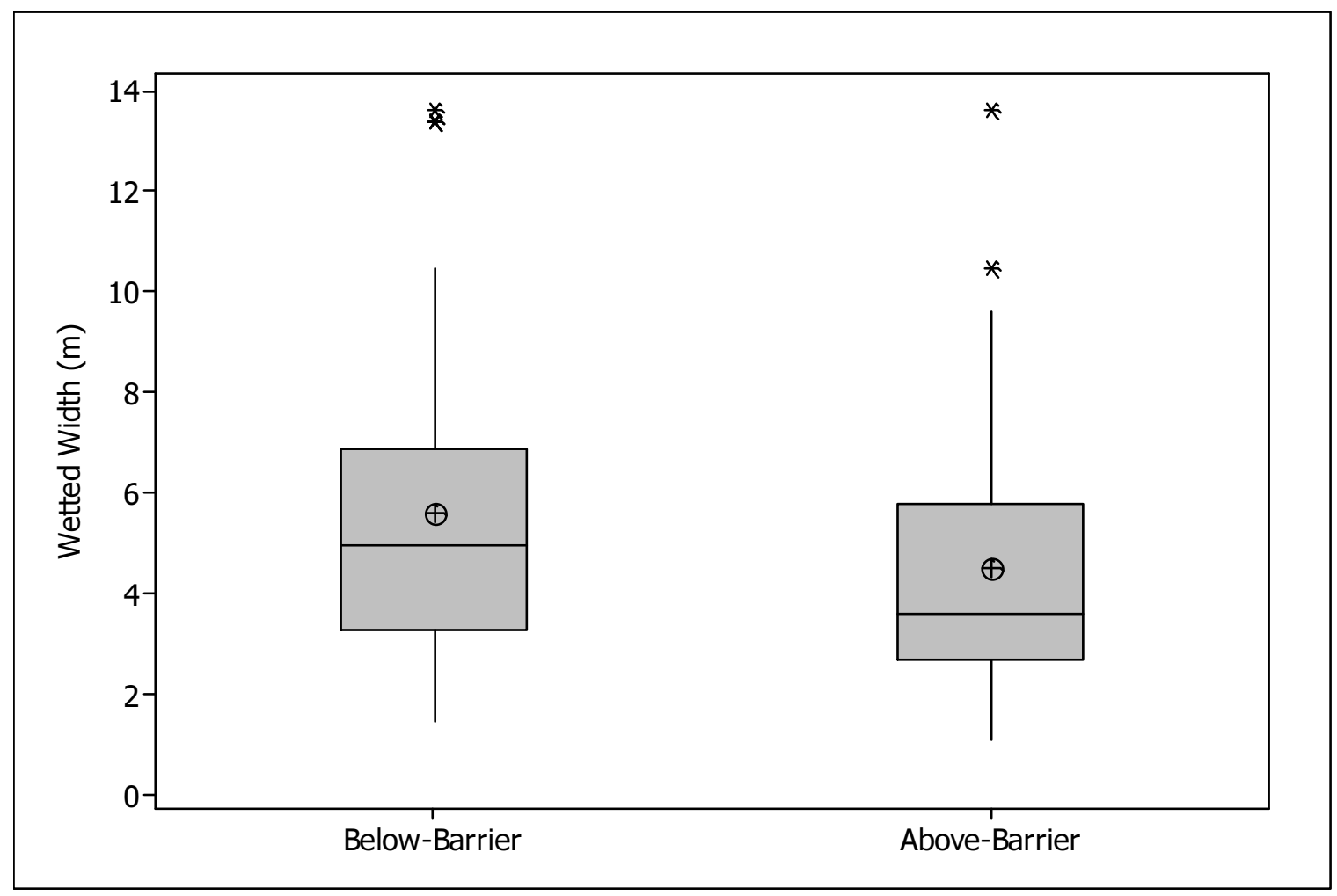

Figure 2.8: Comparison of average wetted width $(\mathrm{m})$ between above (upstream) and below (downstream) barrier fish sampling sites. Wetted width was the only habitat variable measured which showed a significant $(\mathrm{P}=0.041)$ difference between sites regardless of barrier presence or absence. Boxes represent interquartile range with a median bar while the bull's-eye represents the mean value for each group. Whiskers represent the full data range with minimum and maximum values. 


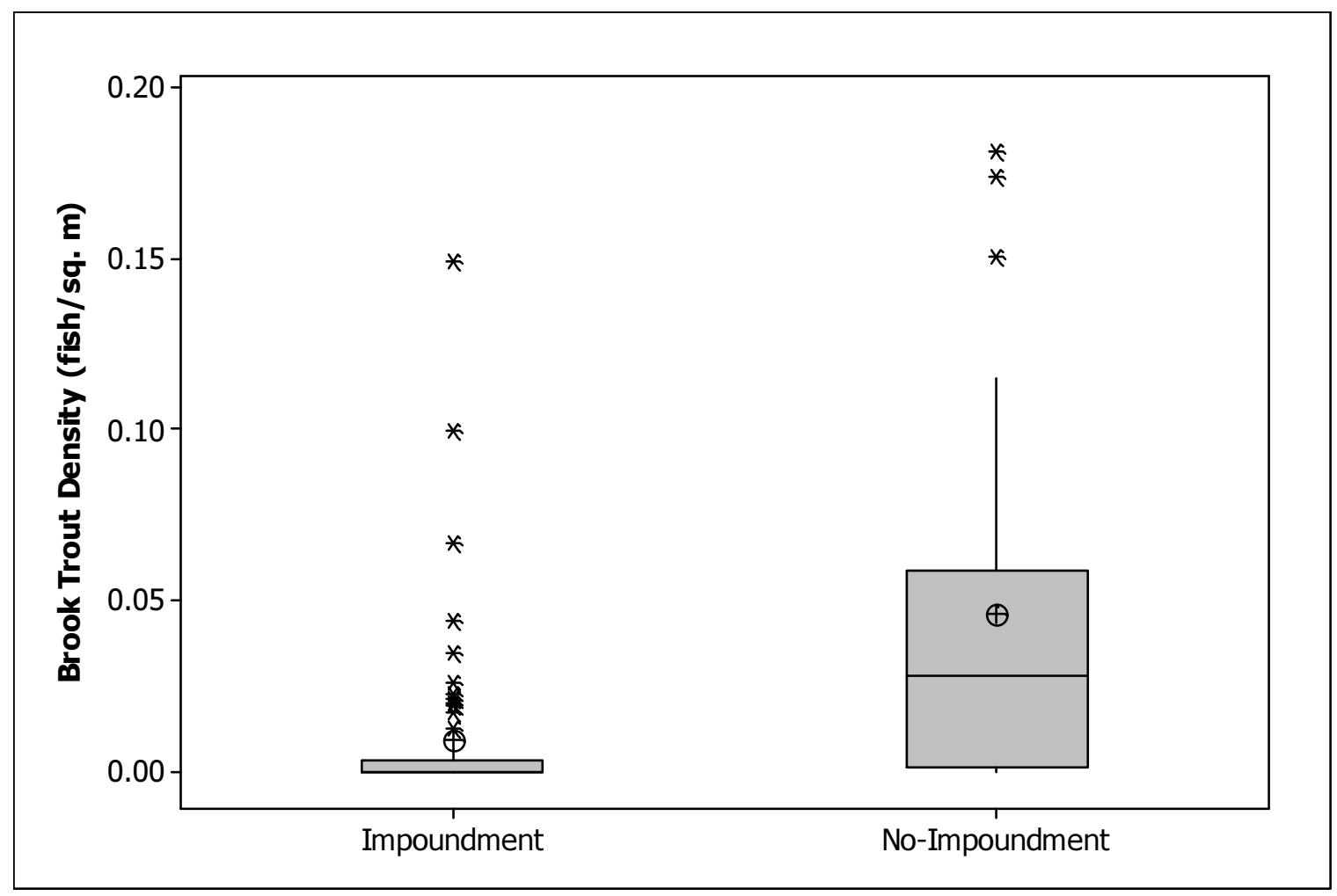

Figure 2.9: Comparison of brook trout density between sites with influence from headwater impoundment and sites without influence from impoundments. Brook trout density was significantly lower in sites with an impoundment present upstream $(\mathrm{P}<0.001)$. Boxes represent interquartile range with a median bar while the bull's-eye represents the mean value for each group. Whiskers represent the full data range with minimum and maximum values. 


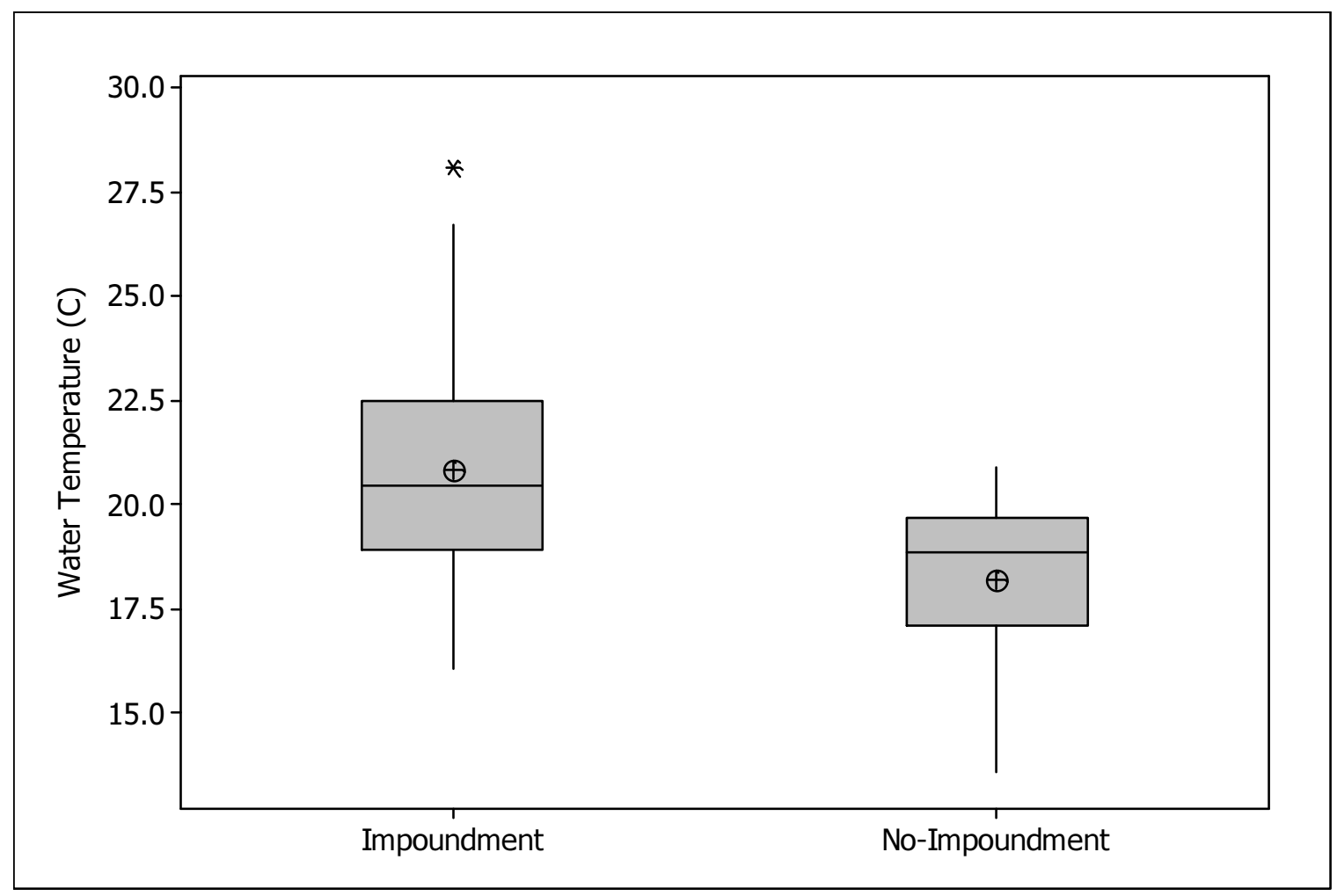

Figure 2.10: Comparison of water temperature between sites influenced by impoundments and sites with no impoundments present. Water temperature was significantly higher in sites sampled where impoundments were present upstream as opposed to those sites where no impoundments were present $(\mathrm{P}<$ 0.001). This may be important in defining potential fish habitat during different seasons. Boxes represent interquartile range with a median bar while the bull's-eye represents the mean value for each group. Whiskers represent the full data range with minimum and maximum values. 


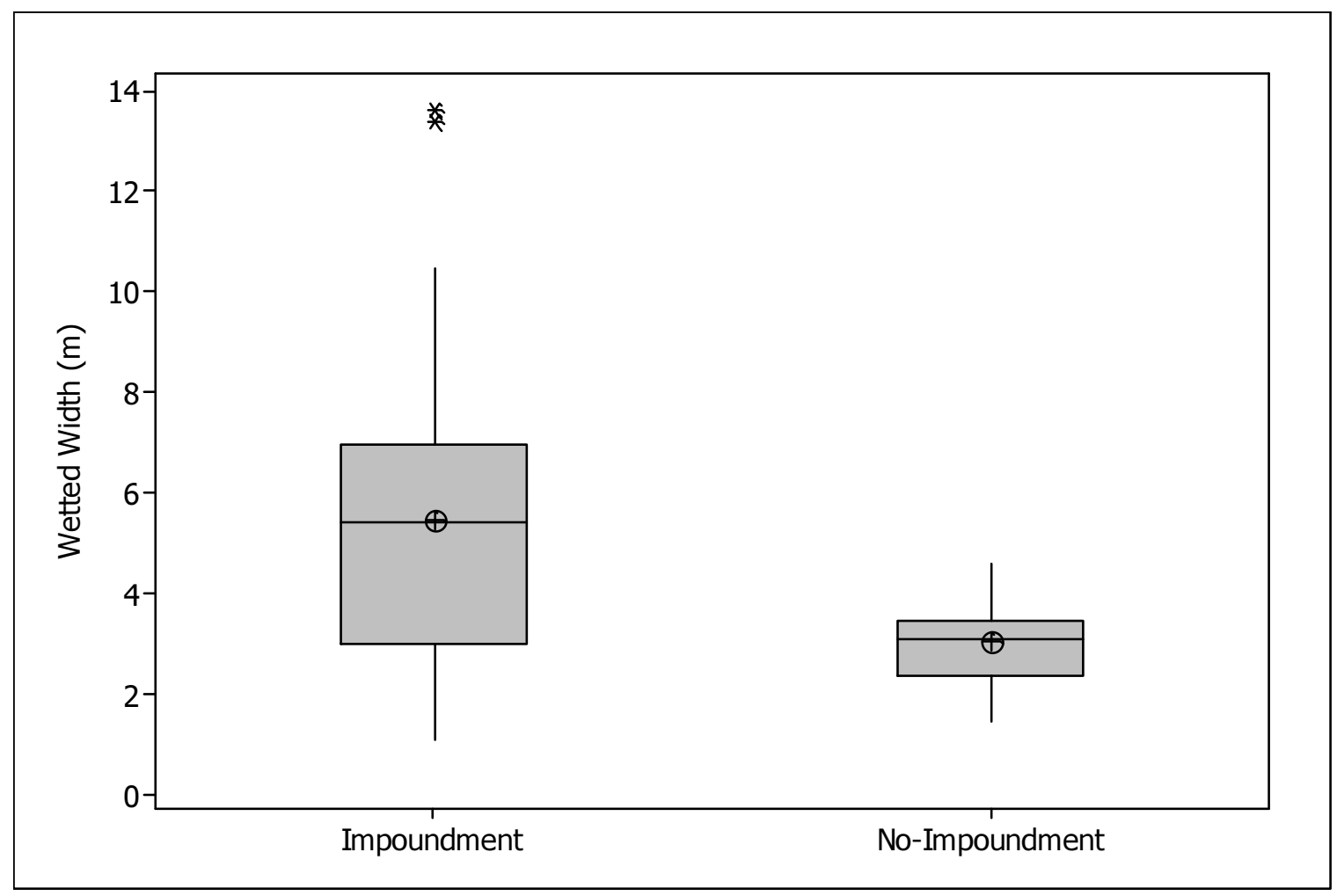

Figure 2.11: Comparison of average wetted width $(\mathrm{m})$ between sites influenced by an impoundment and those sites uninfluenced by impoundments. There is a significant difference $(\mathrm{P}<0.001)$ in average wetted width between sites with impoundments versus sites with no impoundments. This is likely a result of increased flows from impoundment releases and runoff during storm events and may affect fish community structure and composition. Boxes represent interquartile range with a median bar while the bull's-eye represents the mean value for each group. Whiskers represent the full data range with minimum and maximum values. 


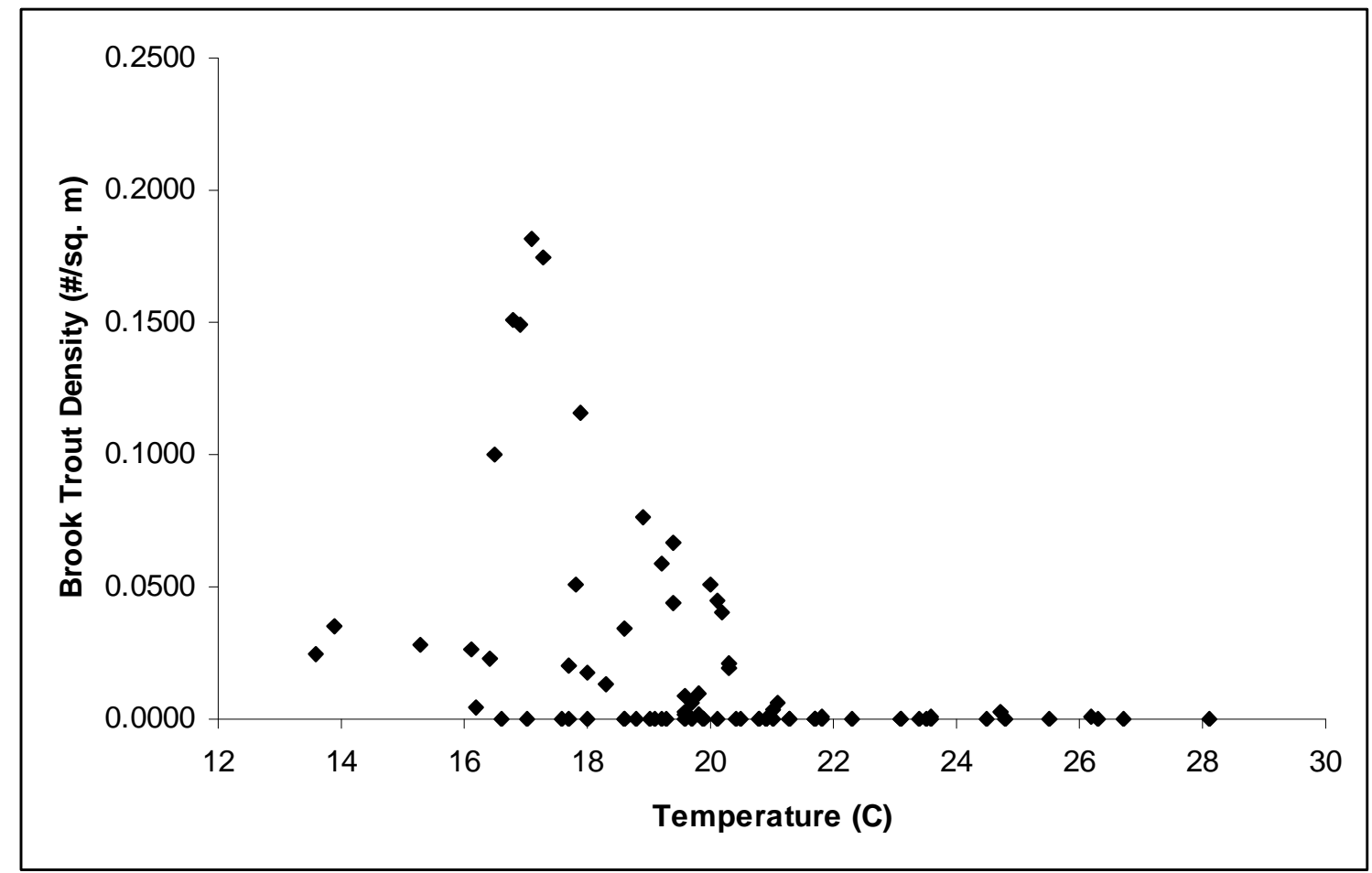

Figure 2.12: Sampled brook trout density $\left(\mathrm{fish} / \mathrm{m}^{2}\right)$ as related to water temperature at each sampling site. Samples were taken during summer months from June-July so water temperatures were near their annual maximums. Almost no brook trout were found in water temperatures above $21^{\circ} \mathrm{C}$. 


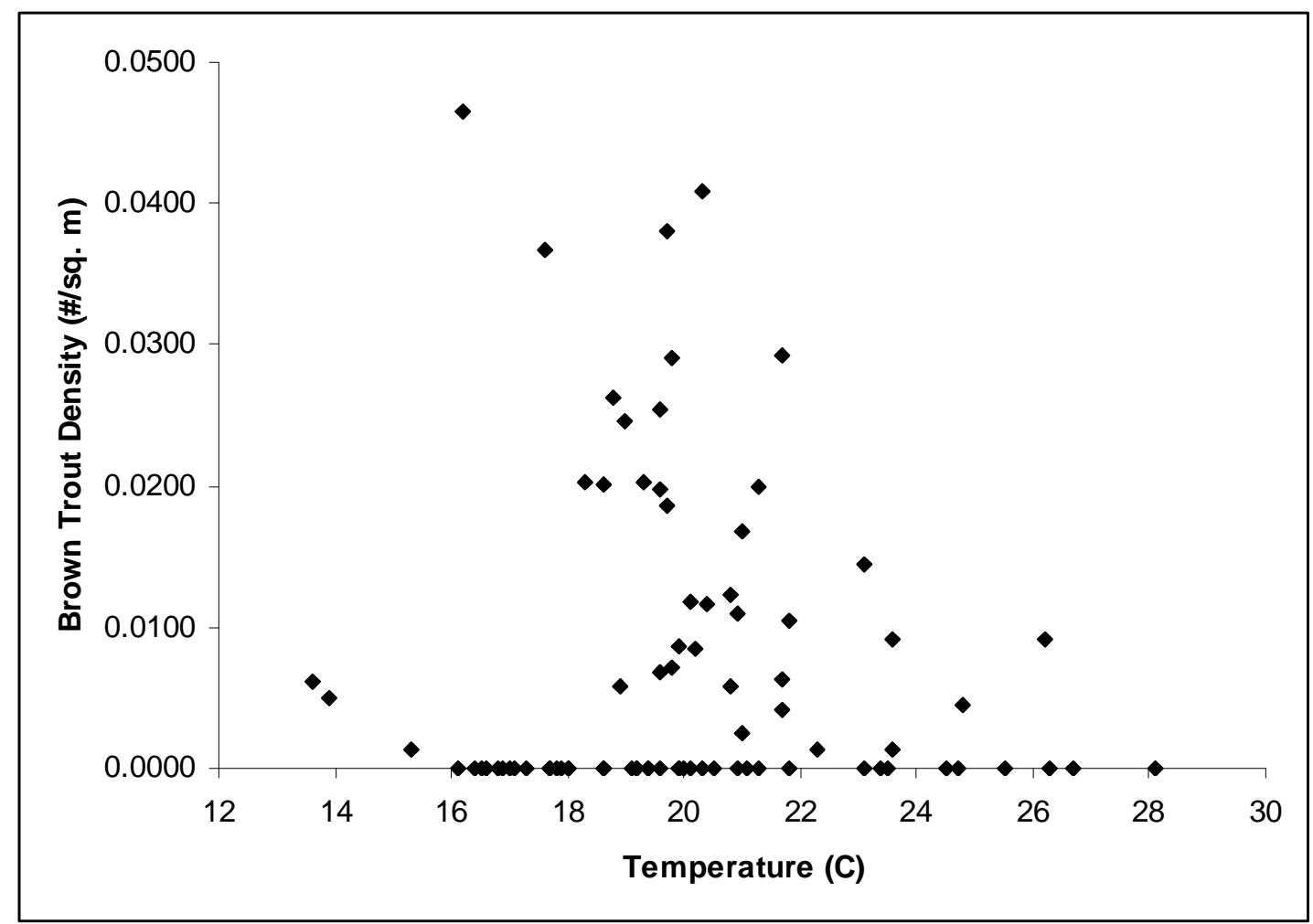

Figure 2.13: Sampled brown trout density (fish $/ \mathrm{m}^{2}$ ) as related to water temperature at each sampling site. Samples were taken during summer months from June-July so water temperatures were near their annual maximums. Brown trout showed a wider range of thermal tolerance than brook trout with some high densities occurring in water temperatures up to $26^{\circ} \mathrm{C}$.

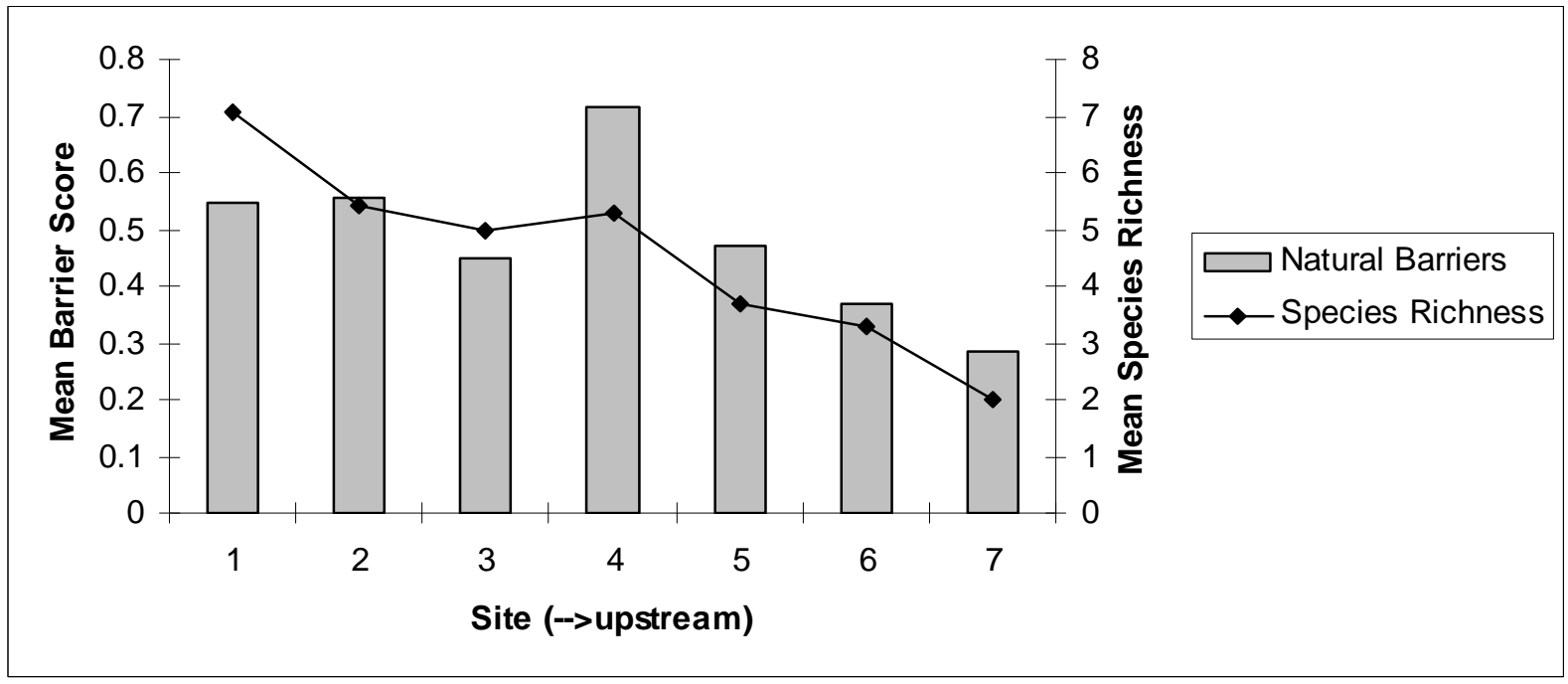

Figure 2.14: Mean natural barrier difficulty score and mean species richness plotted along a longitudinal gradient of sample sites moving from downstream to upstream. 


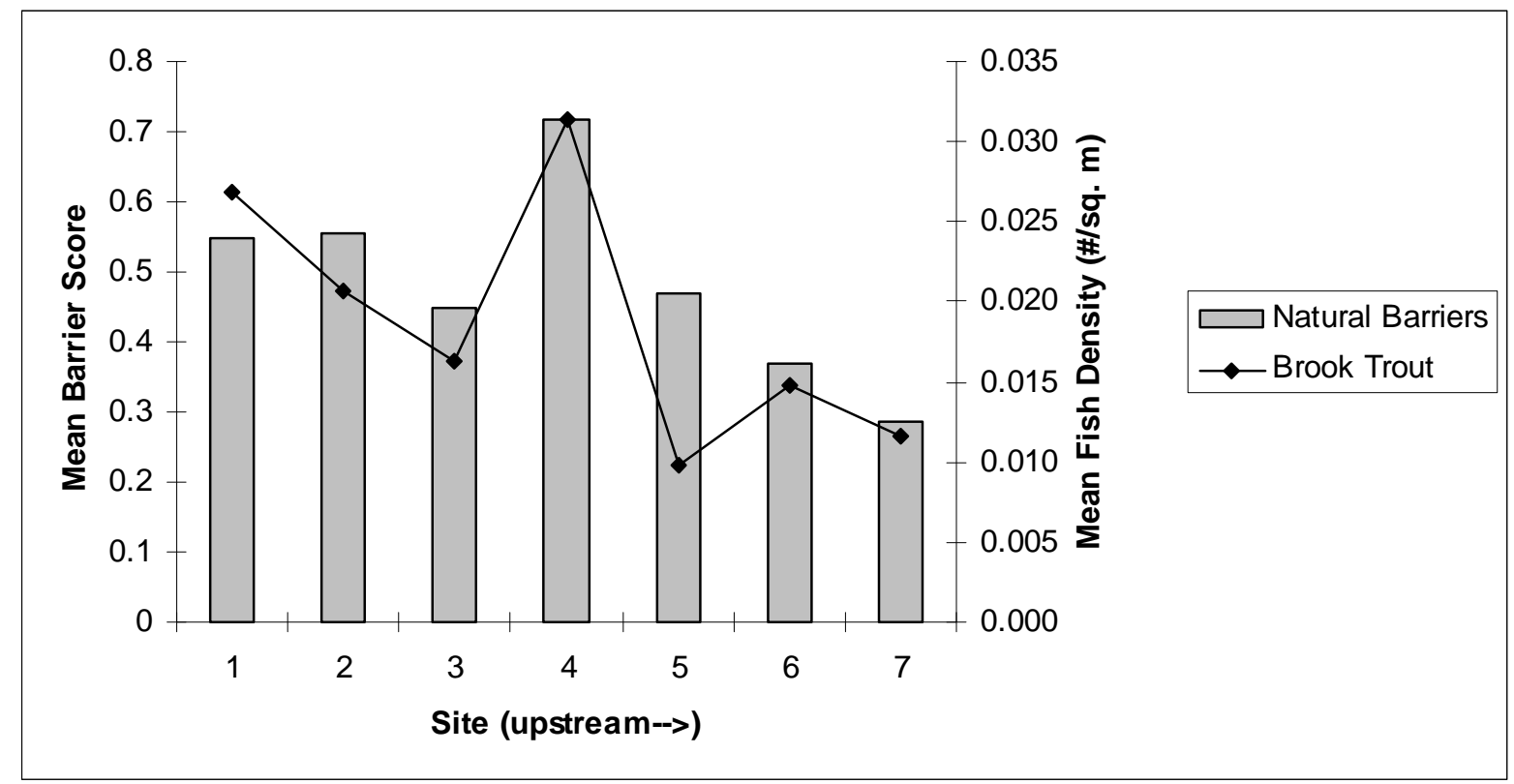

Figure 2.15: Mean natural barrier difficulty score and mean brook trout density plotted along a longitudinal gradient of sample sites moving from downstream to upstream.

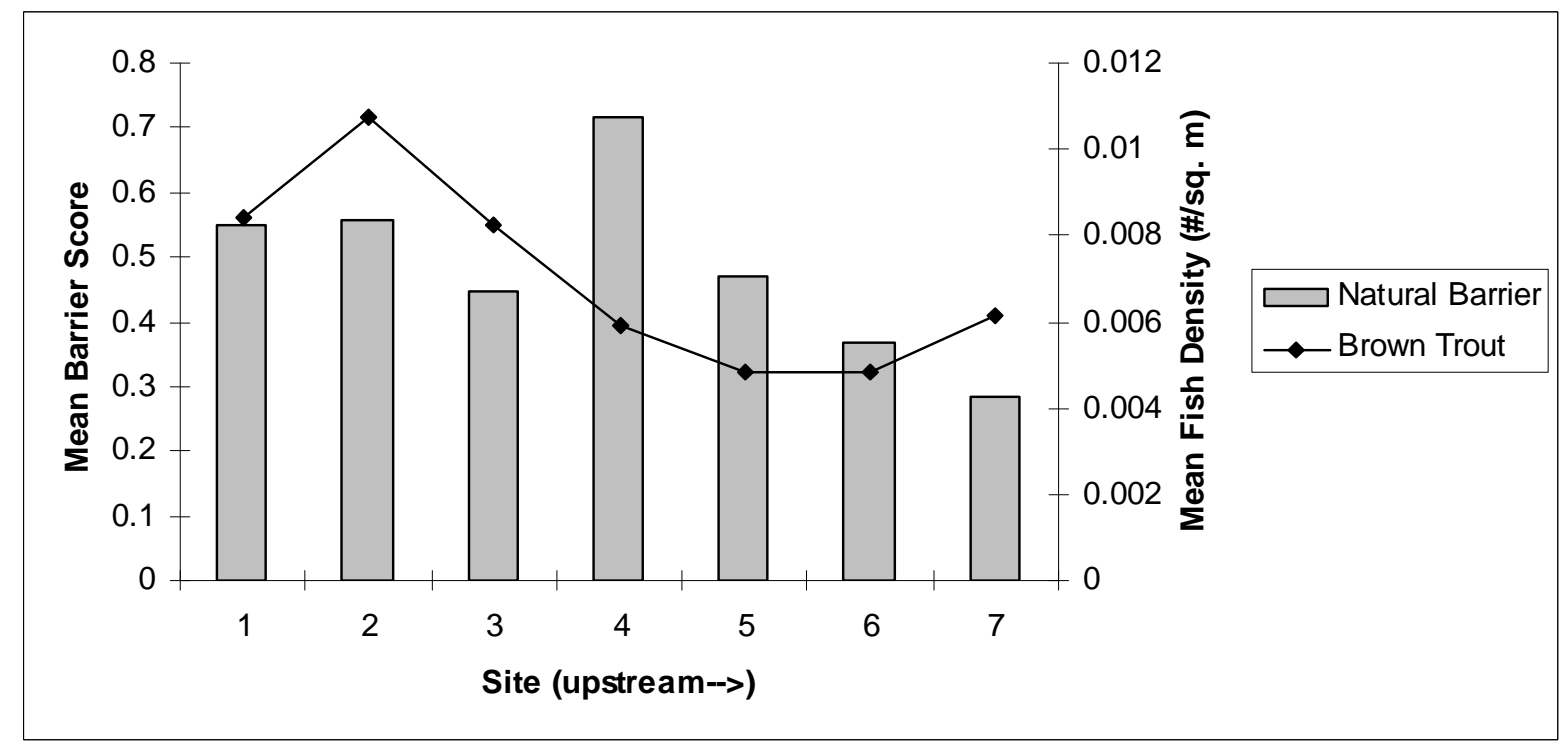

Figure 2.16: Mean natural barrier difficulty score and mean brown trout density plotted along a longitudinal gradient of sample sites moving from downstream to upstream. 


\title{
Chapter 3
}

\section{Predictive Modeling of Natural Barrier Occurrence in Delaware Water Gap National Recreation Area}

\begin{abstract}
Natural barriers can fragment habitat within stream systems and may restrict movements of fishes to potential spawning, foraging, and refuge habitats. Modeling the occurrence of natural stream barriers may allow for better understanding of habitat connectivity and associated conservation and management needs within a given area. The objectives for this study were: 1) identify physical habitat parameters and thresholds for natural dispersal barriers using GIS and LiDAR, and 2) develop predictive models for natural barrier occurrence using logistic regression and map output using rule criteria formed by the models. We conducted 446 surveys of natural barriers within the Delaware Water Gap National Recreation Area and used landscape level attributes such as elevation, slope, geology, and soil type to predict areas of higher natural barrier occurrence probability. Predictive models were influenced by slope, flow accumulation (drainage area), and soil type. Rules criteria were set using the contribution of significant variables and predicted output was mapped across watershed study areas. This research demonstrates the capability of predictive modeling to explain the occurrence of biologically significant phenomena using spatial data. This process could be applied to other study areas in order to reduce sampling effort in the field.
\end{abstract}

\section{Introduction}

As demand for freshwater resources increases globally, issues with aquatic resource preservation and management are being brought to the forefront (Jackson et al. 2001). Aquatic freshwater resources including fish and fish habitat are important to maintain in the face of increasing demand and climate change (Arnell 1999). Climate change modeling for fish habitat and distribution has shown the potential for large decreases in habitat availability in the western U.S. (Rieman et al. 2007) and southern Appalachians (Flebbe et al. 2006). Both western and eastern climate change models predicted losses in habitat for native trout species of up to 99 and 97 percent respectively within the range of current predicted climate change rates for the coming decades. While 
increasing concerns surrounding freshwater demand and climate change accumulate, current knowledge of fish habitat and populations has become even more critical for future conservation and management efforts. One such habitat measure is hydrologic connectivity or the "water-mediated transfer of matter, energy, and/or organisms within or between different parts of the hydrologic cycle" (Pringle 2001), and includes fishes within a stream network. Habitat connectivity plays a key role in fish dispersal throughout a potential range (Weins 2002; Pringle 2003).

Fish move by both necessity and choice, to utilize new habitats, shelter, and food resources (Fausch and Young 1995). Some movement is driven by attraction to spawning or feeding activities while other movement is motivated by avoidance of predators, competitors, and disturbances (Fausch and Young 1995; Harvey 1991). When habitat connectivity is lost due to both natural and artificial barriers, fishes lose their ability to disperse into adjacent habitats and utilize adjacent resources (Thompson and Rahel 1998; Warren and Pardew 1998; Adams et al. 2001; Gibson 2005; Cote et al. 2009). Loss of connectivity can also lead to losses of genetic integrity and recolonization potential following disturbance (Roghair and Dolloff 2005). Habitat fragmentation may also affect the distribution of invasive species by isolating them in certain areas and preventing their migration to other areas (Townsend and Crowl 1991; Fausch et al. 2009).

Different types of barriers exist within lotic systems with differing effects on habitat connectivity. Artificial barriers created by humans include dams, culverts, and other road-stream crossing structures. The effects of dams on stream fish populations have been examined extensively in previous studies (Kanehl et al. 1997; Smith et al. 2000; Jackson et al. 2001; Morita and Yamamota 2002; Herbert and Gelwick 2003; 
Guenther and Spacie 2006). Culverts have also been investigated with some rigor regarding their passability for stream fishes (Thompson and Rahel 1998; Warren and Pardew 1998; Coffman 2005; Burford et al. 2009; Poplar-Jeffers et al. 2009). These barriers can prevent movement of mobile-stream fishes such as brook trout (Salvelinus fontinalis), with potentially negative implications for growth and persistence. While artificial barriers can have profound impacts on habitat connectivity, natural barriers such as waterfalls may also impact fish dispersal potential. Adams et al. (2001) found slopes of $17 \%$ and vertical barriers of $2.5 \mathrm{~m}$ or greater to be considered upstream invasion barriers for nonnative brook trout in western U.S. streams. While natural barriers can create similar losses of habitat connectivity to fishes as artificial barriers, less research has been devoted to their role in aquatic systems (Powers and Orsburn 1985; Townsend and Crowl 1991; Adams 2001). Natural barriers occur throughout aquatic systems in the form of waterfalls, steep cascades, and rock chutes or slides. Occurrences and spatial distributions of barriers within watersheds can greatly affect the habitat connectivity (Cote et al. 2009). Thus, identifying areas of natural barrier occurrence holds great value for stream management and/or research efforts. Finding natural barriers within a system is the first step to understanding what role they play in that system.

Predictive modeling has been employed in ecological studies to identify likely suitable habitat or species home ranges (Ambrosini et al. 2002; Schadt et al. 2002; Phillips et al. 2006; Yost et al. 2008). The main difference between modeling potential distributions of natural barriers and a given species is the lack of movement of waterfalls versus vagile organisms. This can be both an advantage and a challenge to ecological modeling. For one, modeling natural barriers should be easier than modeling organisms 
since they do not move and cannot change preference for habitat based on season or resource availability. Conversely, natural barriers are not dependent on food and shelter as most organisms so their preferred "habitat" may not be as easily defined. The modeling technique is not different, but explanatory variables consider only physical attributes and not those that influence life history characteristics. Traditional modeling using a technique like logistic regression can provide insight into important environmental variables for predicting presence-absence of features of interest, in this case natural barriers (Ambrosini et al. 2002; Schadt et al. 2002). This approach assumes that both presence and absence data are available. If presence-only data are available, a Bayesian probability modeling approach such as maximum entropy modeling (maxent) could be the best modeling solution (Phillips et al. 2006). Defining barriers as functional for fish passage ahead of time allows the use of presence-absence modeling for natural barriers. Given uncertainty in predicted barrier locations, a mapped distribution of likely locations gives us a more realistic "target area" in which barrier presence is more likely than random.

The objectives for this study are to: 1) identify physical habitat parameters and thresholds for natural dispersal barriers using GIS and LiDAR data, and 2) develop predictive models for natural barrier occurrence using logistic regression and maps based on rule criteria formed by the models. By creating predictive models and field protocols, we aim to reduce the amount of field surveys necessary to accurately assess landscape connectivity. By classifying areas prior to field surveys, researchers and agencies may be able to save time and money by prioritizing their efforts for conservation and management. 


\section{Methods}

Field Surveys and Data Collection

We conducted field surveys of natural barriers from 28 June to 30 July 2010 and 6 June to 26 July 2011. We selected sites using two different methods. First, we selected sites across a stream slope gradient using GIS and digital elevation models (DEMs) at $1 \mathrm{~m}^{2}$ resolutions. The DEM was created using LiDAR data acquired by Robinson Aerial Surveys, Inc. by way of the Federal Emergency Management Agency (FEMA). The LiDAR data were acquired in April of 2008 using a nominal point spacing of 1.4 meters with a point density of 0.6. The LiDAR data were collected using accuracy standards suitable for an inherent image scale of 1:1200 which the use of the DEM was at variable map scales. A DEM was created from the LiDAR point returns using TiFFs 6.0 LiDAR processing software by John Young at USGS Leetown Science Center (personal communication March 30, 2012). We used the DEM in a GIS to identify raster grid cells of rapidly changing elevation and slope along stream flow lines. These grid cells were classified into six categories of slope percentage $(0-3 \%, 3-5 \%, 5-12 \%, 12-17 \%, 17-$ $20 \%$, and 20-100\%). We selected these categories based upon literature-derived values for stream slope tolerances of salmonids (Adams et al. 2000, Adams et al. 2001 and Clarkin et al. 2003). A target of approximately 15 barriers from each of six slope categories $(n=90)$ were randomly selected for surveying, but 93 sites were actually surveyed.

In addition to the randomly selected stream slope strata, 17 randomly selected watersheds were intensively surveyed to coincide with fish sampling. These 17 watersheds were randomly selected from a potential 48 within the park and stratified by 
characteristics of elevation, geology, stream order, and stream slope. We conducted the intensive surveys by walking up (or down) a particular watershed and measuring every natural barrier found. Among these 17 watersheds, an additional 353 barrier surveys were conducted, bringing the total number of natural barrier surveys within the park to 446. By selecting sites in these two different ways, we could see the smaller barriers that may have been missed by the LiDAR site selection and better understand the limitations of this selection technique while getting a view of natural barriers throughout different watersheds.

Each natural barrier survey was done in a series of steps. The first step was definition of the location of the barrier within the stream and assessment of the barrier's permanence. This was done to rule out small debris jams within the stream which could act as temporary barriers to fish passage. We would then define the barrier type based upon its physical appearance. We defined barriers as waterfalls, cascades, or chute/slides according to previous research definitions of each (Powers and Orsburn 1985; Mabin 2000). Each barrier was also given a unique alphanumeric identification typically associated with its location within a given watershed.

The second step involved collection of general site information including water temperature, $\mathrm{pH}$, and barrier material such as bedrock, boulder, etc. We also took a digital photograph of the site and recorded its exact location using a Trimble GeoXT global positioning system (GPS). Additionally, we recorded locations on a handheld Garmin GPS to act as a back-up to the Trimble location points. Any interesting site features were noted including the presence of fish or specific attributes of the barrier itself. 
The third step was comprised of a physical survey of the natural barrier to determine its relative difficulty for fish passage. These surveys were conducted with a Leica Geosystems DISTO D8 laser distance meter. The DISTO laser distance meter would be set up on a tripod immediately downstream of a natural barrier and steps would be measured using the slope and height function. This function could assess both the slope and height of a barrier step while taking into account the distance the tripod was set up from the barrier itself. The procedure was dependent on the type of barrier being surveyed. For example, chute/slide barriers, which do not require vertical leaps for fish passage, were measured in terms of slope and distance. In contrast, waterfalls or cascades were measured in terms of vertical height of each step along with that step's slope since most steps were not absolutely vertical. Depth of jump/resting pools were also recorded within a half meter of the associated barrier step to represent the likely jumping point for a fish attempting to pass the barrier in an upstream direction. A barrier step was defined by the presence of a resting pool before some vertical or highly sloped component of the barrier. We defined a resting pool as a mostly flat area with enough surface area to support an adult fish of the desired species. Resting pool size and depth varies naturally as the discharge of the stream changes seasonally. Therefore, resting pools cannot be completely ascertained but must be selected based on adequate area for the desired species. These surveys lead to the classification of each barrier based upon its severity or relative difficulty for fish passage.

\section{Barrier Classification}

Variation in stream morphology and species perception of barriers creates challenges in barrier classification. To standardize decisions of barrier classification, we 
used the maximum value for brook trout jump height as found by Kondratieff and Myrick (2006) as the minimum qualification for a measurable barrier. Maximum jump heights for brook trout are based on the depth of the resting pool $(0.435 \mathrm{~m}$ and $0.735 \mathrm{~m}$ for resting pools of $<10 \mathrm{~cm}$ and $\geq 40 \mathrm{~cm}$, respectively; Kondratieff and Myrick 2006). Maximum passable slopes for brook trout are based upon the maximum values found in literature between sustained brook trout populations and the maximum slope and distance brook trout may travel in a short burst of swimming/leaping (Adams et al. 2000; Adams et al. 2001; Clarkin et al. 2003; and Dunham et al. 1999). We averaged the values found for each group and estimated a maximum passable slope of $20 \%$ over a distance of 20 meters or less and $11.5 \%$ with no distance limit. Maximum slopes were used to calculate barrier difficulty when there was adequate water depth for a fish to swim through the barrier; otherwise vertical jump height was used.

For natural barrier classification, a standardized scoring system was created for each step of each barrier. For each step of a natural barrier, the step would receive points based on its vertical drop and slope. For the vertical drops: $<0.735 \mathrm{~m}=1$ point, $>0.735 \mathrm{~m}$ $<2 \mathrm{~m}=5$ points, and $>2 \mathrm{~m}=10$ points. For the slopes: $0-11.5 \%=1$ point, $11.5-20 \%=2$ points, $20-50 \%=3$ points, $50-100 \%=4$ points, and $>100 \%=5$ points. These point totals for each step were added up and divided by the number of steps in each barrier to give a standardized value for the barrier overall. Each overall barrier score was then compared against all other barrier scores within the study area to create a relative difficulty index for the entire study area with a maximum value of one. As the scores approach one, the barrier becomes more severe and therefore difficult for the fish to pass. 


\section{Predictive Modeling}

We used an average nearest neighbor test of spatial association using Euclidean distance to determine if there were any significant patterns in the spatial distribution of natural barrier occurrence. This provided insight into whether the barrier occurrence points were located in a spatial pattern of clustering, dispersal, or randomness. These tests were done using ArcGIS v10, spatial statistics tools (ESRI). Once spatial patterns were revealed, we could begin to develop ways to describe those patterns using predictive modeling techniques. We sought to describe the locations that were more or less likely to contain natural barriers based upon landscape level data that could be provided remotely.

The logistic regression model was created using the statistical software $R$ ( $R$ Development Core Team 2008). Both presence and absence data were required for the logistic regression model. Barriers which received scores below a certain threshold to have a functional effect on fish communities were considered absence points while those barriers with scores above the threshold were considered presence points. Based upon data collection and analysis in the previous chapter, we set the threshold value at 0.4 meaning that barriers with difficulty scores below this value were considered absences in the regression while barriers with a difficulty score above this threshold were considered presences in the regression. This allows the definition of "biologically functional barriers" to be used for those barriers with a difficulty score of greater than 0.4 . The response variable was the presence (1) of a barrier according to our biologically-derived definition versus the absence $(0)$ of a barrier. The explanatory variables that were used in the logistic model included elevation, aspect, slope, flow accumulation number, geology 
type, and soil type. These data were also prepared and created using ArcGIS v10 (ESRI). The geology data came from the National Park Service Geologic Resource Evaluation Program and is represented by a 1:24,000 inherent image scale. The soil data for the Pennsylvania side of the study area came from data resources found on Pennsylvania Spatial Data Access (PSDA, http://www.pasda.psu.edu/) and are available for public access and use. Data for New Jersey sites came from the New Jersey Department of Environmental Protection (http://www.state.nj.us/dep/gis/) and the Natural Resources Conservation Service (NRCS) soil data mart (http://soildatamart.nrcs.usda.gov/). Soil data are represented by a 1:20,000 inherent scale.

Natural barriers were modeled using landscape-level data. The continuous variables included were elevation, aspect, slope, and flow accumulation number. Categorical variables included geology type and soil type. Aspect is presented in a geographical context with the values representing the cardinal direction a slope faces. The values are typically presented using a cosine transformation in order to represent a 360 degree plane with a more simple scale of -1 to 1 which represents relative "northness" of the slope. That transformation was used for these data and they showed a wide range of values between -0.99 to 1 . Slope was measured as percent rise in the elevation over some distance. Flow accumulation is a way to derive watershed drainage area at a given point within a stream network. It is easily created using a DEM in ArcGIS and essentially represents the number of cells within a DEM that flow to any particular cell. These cell values can be converted to drainage area when cell size (and subsequently cell area) is known. 
Model performance was assessed after prediction of natural barriers using different combinations of predictors. For the regression models, variable importance was assessed using significance of p-values for variables used in prediction and the overall model performance using Akaike information criterion (AIC) (Akaike 1974) values for each successive model run with different explanatory variables included. The best performing model (lowest AIC value) was used to determine important landscape variables for prediction of barrier presence and define rule criteria for mapping. Using coefficients and variable relationships from regression models, a set of rule criteria were created and applied to individuals watersheds using ArcGIS v10 (ESRI). Rules criteria were used to define areas of higher or lower barrier occurrence likelihood using the raster calculator in ArcGIS v10 (ESRI).

\section{Results}

\section{Spatial Distribution of Natural Barriers}

Distribution of natural barriers across the study area was not random. A test for spatial association using the average nearest neighbor function in ArcGIS v10 spatial statistics tools revealed a significantly clustered pattern $(\mathrm{P}<0.001)$. This tested against the null hypothesis of a random spatial distribution and showed that barriers do not occur randomly throughout the study area. This initial information is critical for defining predictive models and justifying the use of such models. With a random distribution of barrier occurrence points, there would be no way to model predictive locations based upon landscape factors. Among the 17 watersheds surveyed, all contained natural barriers that were surveyed (Table 3.1). The mean value among all watersheds was 
$19.78 \pm 2.68$ barriers per watershed. This number was undoubtedly affected by the amount of stream kilometers covered in the survey and thus we took an average number of barriers per stream kilometer which was $5.4 \pm 1.27$ barriers per kilometer across all watersheds. Watersheds in New Jersey had a higher mean number of barriers per kilometer (8.34) than watersheds in Pennsylvania (4.57) but this difference was not significant $(\mathrm{P}=0.432$, Figure 3.1).

\section{Model Development}

Natural barriers ranged in elevation from 88-399 meters with a mean of 187.6 \pm 2.64 meters and a median of 186 meters. Thus, natural barriers were found throughout the continuum of stream networks from headwaters to near the mouth but were most commonly found in the middle elevations. The mean north-ness (aspect) value was $0.2803 \pm 0.0291$ and the median value 0.54 . Slope ranged from $0-105.3 \%$ with a mean value of $13.02 \pm 0.69 \%$ and a median value of $10.0 \%$. Hence, barriers occurred over a large range of land gradients but were most common in noticeably sloping. The flow accumulation number values ranged from 1135 cells (2.84 hectares) to 16971912 cells (42429.78 hectares) with a mean value of $1448394 \pm 137443$ cells $(3620.99 \pm 343.61$ hectares) and a median value of 401348 cells (1003.37 hectares). This shows that natural barriers were found in a wide range of positions along the stream continuum from headwaters to mouth but were more common in smaller drainage areas such as the upper elevations of streams. Natural barriers also showed occurrence across a wide range of both geology and soil types. 
The logistic regression model predicts barrier presence and absence as defined by the barrier difficulty scores ranging from 0 (non-barrier) to 1 (extremely difficulty barrier for fish passage). Several models were tested using different combinations of explanatory variables. Ultimately, the model with the lowest AIC value (536.86) included only slope, flow accumulation number, and soil type (Table 3.2). According to the Akaike weights which represent conditional probability of each model, the model using slope, flow accumulation number, and soil type is the most probable model with a relative weight of 0.52 (Table 3.2). A second model with Akaike weight of 0.38 includes the same variables with the addition of aspect. Since the $\triangle$ AIC value for this model is less than two, it must also be considered as a plausible model to explain these natural barrier data (Burnham and Anderson 2002). Both slope and flow accumulation number were significant contributors to the logistic regression model $(\mathrm{P}=0.0137 \& 0.0109$ respectively) (Table 3.3). Soil type only had one significantly contributing group which was for type OprE $(\mathrm{P}=0.0075)$ (Table 3.3). This soil type is synonymous with Oquaga rock outcrops on 35-60\% slopes (USDA Soil Survey Sussex County, NJ). The combination of high rockiness and high slope results in a high erodibility (USDA Soil Survey). Generally, barrier presence increases as slope increases, increases as flow accumulation number decreases, and increases wherever the presence of the OprE soil type is found.

\section{Mapping and Extrapolation of Results}

Based upon the significant variables from the regression and the contribution of each variable, we created a set of rules criteria for mapping the barrier predictions. These 
rules were then applied to the landscape data for a respective watershed. Mapped output was used to delineate areas which are more likely to contain natural barriers based upon the regression-derived rules set. The rules criteria are derived from the significant findings in the regression. The first rule is set by the categorical variable for soil type. Since the only significant soil type for barrier presence was the OprE formation, any area with this soil type is automatically included in the predictive area for barrier occurrence. The second rule is based upon slope values and states that if a given land slope value is greater than or equal to 20 percent it is prone to natural barrier occurrence (Figure 3.2). The third and final rule is based upon the flow accumulation number and gives a range between 500 cells (3.09 acres) and $80 \%$ of the largest flow accumulation value in a given watershed. These areas are modeled to have a higher probability of barrier occurrence (Figure 3.3). The lower bound of this flow accumulation range is to ensure that areas of suitable drainage are targeted (i.e. streams). The upper bound is more defining since it controls where in the stream the likelihood decreases since natural barriers are more common in the headwater areas than in the lower elevation areas near the mouth of streams. When combined, these three rules can be used to define areas of likely barrier occurrence within a given watershed (Figures 3.4 and 3.5). These rules may also be used to extrapolate prediction of barrier occurrence into other unsurveyed watersheds or even other geographic areas. However, extrapolation into other geographic areas should be done with caution since landscape-level predictor variables may be different and could lead to false predictions.

\section{Discussion}


Suitability modeling using GIS is common in fisheries research (Brown et al. 2000; Vincenzi et al. 2006; Gillenwater et al. 2006) but is mostly associated with habitat suitability for fish spawning or resource needs. Natural barriers influence the connectivity between habitats and can therefore be similarly influential with respect to fish population/community dynamics. I was able to ascertain specific landscape variables that are important for predicting the presence of functional natural barriers within the study area. Those variables were slope, flow accumulation number, and soil type. Slope is logically tied to natural barrier occurrence and can define both the type and severity of barrier (Powers and Orsburn 1985). A positive relationship between barrier occurrence and slope also makes sense when the other contributing variables are considered. Flow accumulation number was shown to have a negative relationship with barrier occurrence which means barriers occurred more often in areas with lower flow accumulation numbers. Areas with lower flow accumulation numbers are typically considered headwaters (if not ephemeral). These areas are more inclined to steep, turbulent streams with plunge pool formations within the channel structure. Finally, soil type is interactive with both slope and flow accumulation in the occurrence of natural barriers. This is because erodible soils on higher slopes with turbulent water courses flowing over them are prone to step formation and subsequent barrier complexes.

This research focused on naturally occurring barriers as opposed to humancreated barriers such as dams or culverts. Therefore, the priority here is not so much to manage fisheries around these naturally occurring barriers, but rather to take note of their patterns of occurrence and incorporate that into a working body of knowledge. Multiple testable hypotheses can come from research such as this and may follow lines of logical 
questioning. First, do headwater areas with more barriers act as a refuge against invasion and/or competition for the relatively low number of species that inhabit these areas? Also, do natural barrier effects differ seasonally based on flow regime and available alternative routes of passage? Finally, are natural barriers necessary in some systems to maintain niches, trophic structure, and ultimately species diversity? There is already some evidence that these questions are testable and scientifically relevant to fish ecology (Bozek and Hubert 1992; Schlosser 1995). Further evidence using spatial data is essential to understanding these issues across differing geographic areas.

\section{Limitations and Modeling Considerations}

Suitability modeling is a simple and useful way to combine information to aid in understanding of complex issues and ultimately decision-making. However, care must be taken to understand and account for error within both the source data and the methods used to reach a final output (Yoon 1989; Veregin 1995). Errors in initial data may propagate throughout the analyses and create larger issues with validity of results. Also, subjective decisions for use of weighting criteria may also greatly affect the validity of the final output. This study used rules criteria which were defined by a logistic regression output and interpretation of those regression results. This could lead to some disagreement among practitioners regarding important predictions and thresholds. However, an advantage to this approach is that it allows for the discussion of weighting criteria and variable importance by experts and subsequent refinement of the models and results with relative ease. Additionally, model predictions could benefit from validation 
using random points set aside from the original dataset. This would give a better estimate of the accuracy and subsequent limitations of these models.

Another issue with this study which should be addressed is the use of a conservative Boolean suitability mapping approach. This method is conservative because it only allows areas within the study zones to be defined as either "suitable" or "not suitable". This binary result leaves out many areas that may have some suitability but do not meet all the criteria. A more liberal approach such as fuzzy membership functions allows for areas to be classified along a continuous range of suitability, therefore making the final decisions less deterministic. Another type of approach could be the use of Bayesian probability modeling which uses training data to develop prior and posterior probabilities based upon the characteristics of the known training sites to predict a probability surface across a given area for unknown sites. These probability distributions can then be used to extrapolate predictions into other areas using the same habitat data sets (Aspinall 1994). These methods both work under the assumptions that we rarely have perfect, error-free information and must decide within the best available range that the data allows. Thus, there is potential to successfully model the occurrence of natural barriers and other such phenomena in many different ways with various techniques. The exploration of such spatial analysis techniques will continue to be valuable for understanding the ecological functions and interactions between biota and habitat.

\section{Literature Cited}

Adams, S.B., C.A. Frissell, and B.E. Rieman. 2001. Geography of invasion in mountain streams: consequences of headwater lake fish introductions. Ecosystems 4: 296307. 
Adams, S.B., C.A. Frissell, and B.E. Rieman. 2000. Movements of nonnative brook trout in relation to stream channel slope. Transactions of the American Fisheries Society 129: 623-638.

Akaike, H. 1974. A new look at the statistical model identification. IEEE Transactions on Automatic Control 19: 716-723.

Ambrosini, R., Bolzern, A. M., Canova, L., Arieni, S., Møller, A. P. and Saino, N. 2002. The distribution and colony size of barn swallows in relation to agricultural land use. Journal of Applied Ecology 39: 524-534.

Arnell, N.W. 1999. Climate change and global water resources. Global Environmental Change 9: 31-49.

Aspinall, R. 1992. An inductive modeling procedure based on Bayes' theorem for analysis of pattern in spatial data. International Journal of Geographical Information Systems 6: 105-121.

Bozek, M. A., and W. A. Hubert. 1992. Segregation of resident trout in streams as predicted by three habitat dimensions. Canadian Journal of Zoology 70: 886-890.

Brown, S.K., K.R. Buja, S.H. Jury, M.E. Monaco, and A. Banner. 2000. Habitat suitability index models for eight fish and invertebrate species in Casco and Sheepscot Bays, Maine. North American Journal of Fisheries Management 20: 408-435.

Burford, D.D., T.E. McMahon, J.E. Cahoon, and M. Blank. 2009. Assessment of trout passage through culverts in a large Montana drainage during summer low flows. North American Journal of Fisheries Management 29: 739-752.

Burnham, K.P., D.R. Anderson. Model Selection and Multi-model Inference: A Practical Information-theoretic Approach. New York: Springer, 2002. Print.

Clarkin, K., A. Connor, M.J. Furniss, B. Gubernick, M. Love, K Moynan, and S.W. Musser. 2003. National inventory and assessment procedure for identifying barriers to aquatic organism passage at road-stream crossings. U.S. Forest Service, San Dimas, CA.

Coffman, J.S. 2005. Evaluation of a predictive model for upstream fish passage through culverts. James Madison University.

Cote, D., D.G. Kehler, C. Bourne, and Y.F. Weirsma. 2009. A new measure of longitudinal connectivity for stream networks. Landscape Ecology 24: 101-113.

Dunham, J. B., M. M. Peacock, B. E. Rieman, R. E. Schroeter, and G. L. Vinyard. 1999. Local and geographic variability in the distribution of stream-living Lahontan cutthroat trout. Transactions of the American Fisheries Society 128: 875-889.

ESRI 2011. ArcGIS Desktop: Release 10. Redlands, CA: Environmental Systems Research Institute.

Fausch, K. D., B. E. Rieman, J. B. Dunham, M. K. Young, and D. P. Peterson. 2009. Invasion versus isolation: trade-offs in managing native salmonids with barriers to upstream movement. Conservation Biology 23: 859-870.

Fausch, K. D. and M. K. Young. 1995. Evolutionary significant units and movement of resident stream fishes: a cautionary tale. Pages 360-370 in J. L. Nielsen, editor. Evolution and the aquatic system: defining unique units in population conservation. American Fisheries Society, Symposium 17, Bethesda, Maryland. 
Flebbe, P. A., L. D. Roghair, and J. L. Bruggink. 2006. Spatial modeling to project southern Appalachian trout distribution in a warmer climate. Transactions of the American Fisheries Society 135: 1371-1382.

Gibson, R. J., R. L. Haedrich, and C. M. Wernerheim. 2005. Loss of fish habitat as a consequence of inappropriately constructed stream crossings. Fisheries 30: 10-17.

Gillenwater, D., T. Granata, and U. Zika. 2006. GIS-based modeling of spawning habitat suitability for walleye in the Sandusky River, Ohio, and implications for dam removal and river restoration. Ecological Engineering 28: 311-323.

Guenther, C. B., and A. Spacie. 2006. Changes in fish assemblage structure upstream of impoundments within the upper Wabash River basin, Indiana. Transactions of the American Fisheries Society 135: 570-583.

Harvey, B. C. 1991. Interactions among stream fishes: predator-induced habitat shifts and larval survival. Oecologia 87: 29-36.

Herbert, M. E., and F. P. Gelwick. 2003. Spatial variation of headwater fish assemblages explained by hydrologic variability and upstream effects of impoundment. Copeia 2003: 273-284.

Jackson, R.B., S.R. Carpenter, C.N. Dahm, D.M. McKnight, R.J. Naiman, S.L. Postel, and S.W. Running. 2001. Water in a changing world. Ecological Applications 11: 1027-1045.

Kanehl, P.D., J. Lyons, and J.E. Nelson. 1997. Changes in the habitat and fish community of the Milwaukee River, Wisconsin, following removal of the Woolen Mills Dam. North American Journal of Fisheries Management 17: 387-400.

Kondratieff, M.C. and C.A. Myrick. 2006. How high can brook trout jump? A laboratory evaluation of brook trout jumping performance. Transactions of the American Fisheries Society 135: 361-370.

Mabin, M.C.G. 2000. In search of Australia's highest waterfalls. Australian Geographical Studies 38: 85-90.

Morita, K. and S. Yamamoto. 2002. Effects of habitat fragmentation by damming on the persistence of stream-dwelling charr populations. Conservation Biology 16: 1318-1323.

NJDEP GIS - Bureau of Geographic Information Systems. The Official Web Site for The State of New Jersey. New Jersey Department of Environmental Protection, 31 Jan. 2012. Web. 11 Jan. 2012. <http://www.state.nj.us/dep/gis/>.

Pennsylvania Spatial Data Access - The Pennsylvania Geospatial Data Clearinghouse. Penn State Institutes of Energy and the Environment. Web. 11 Jan. 2012. $<$ http://www.pasda.psu.edu/>.

Phillips, S. J., R.P. Anderson, and R.E. Schapire. 2006. Maximum entropy modeling of species geographic distributions. Ecological Modeling 190: 231-259.

Poplar-Jeffers, I.O., J.T. Petty, J.T. Anderson, S.J. Kite, M.P. Strager, and R.H. Fortney. 2009. Culvert replacement and stream habitat restoration: implications from brook trout management in an Appalachian watershed, USA. Restoration Ecology 17: 404-413.

Powers, P.D. and J.F. Orsburn. 1985. Analysis of barriers to upstream fish migration: an investigation of the physical and biological conditions affecting fish passage success at culverts and waterfalls. Final Project Report for Bonneville Power Administration. Albrook hydraulics laboratory - Washington State University. 
Pringle, C.M. 2001. Hydrologic connectivity and the management of biological reserves: a global perspective. Ecological Applications 11: 981-998.

Pringle, C. 2003. What is hydrologic connectivity and why is it important? Hydrological Processes 17: 2685-2689.

R Development Core Team (2008). R: A language and environment for statistical computing. R Foundation for Statistical Computing, Vienna, Austria. ISBN $\underline{3}$ 900051-07-0, URL http://www.R-project.org.

Rieman, B., D. Isaak, S. Adams, D. Horan, D. Nagel, C. Luce, and D. Myers. 2007. Anticipated climate warming effects on bull trout habitats and populations across the Interior Columbia River basin. Transactions of the North American Fisheries Society 136: 1552-1565.

Roghair, C. N., and C. A. Dolloff. 2005. Brook trout movement during and after recolonization of a naturally defaunated stream reach. North American Journal of Fisheries Management 25: 785-790.

Schadt, S., Revilla, E., Wiegand, T., Knauer, F., Kaczensky, P., Breitenmoser, U., Bufka, L., Červený, J., Koubek, P., Huber, T., Staniša, C. and Trepl, L. 2002. Assessing the suitability of central European landscapes for the reintroduction of Eurasian lynx. Journal of Applied Ecology 39: 189-203.

Schlosser, I. J. 1995. Critical landscape attributes that influence fish population dynamics in headwater streams. Hydrobiologia 303: 71-81.

Smith, L.W., E. Dittmer, M. Prevost, and D.R. Burt. 2000. Breaching of a small irrigation dam in Oregon: a case history. North American Journal of Fisheries Management 20: 205-219.

Soil Data Mart - Home. Natural Resources Conservation Service. Web. 12 Jan. 2012. $<$ http://soildatamart.nrcs.usda.gov/>.

Soil Survey of Sussex County, New Jersey. Rep. United States Department of Agriculture and Natural Resources Conservation Service. Web. 22 Jan. 2012. <http://soils.usda.gov/survey/online_surveys/new_jersey/NJ037/Sussex_NJ.pdf>.

Thompson, P.D. and F.J. Rahel. 1998. Evaluation of artificial barriers in small rocky mountain streams for preventing the upstream movement of brook trout. North American Journal of Fisheries Management 18: 206-210.

Townsend, C.R. and T.A. Crowl. 1991. Fragmented population structure in a native New Zealand fish: an effect of introduced brown trout? Oikos 61: 347-354.

Veregin, H. 1995. Developing and testing of an error propagation model for GIS overlap operations. International Journal of Geographical Information Systems 9: 595619.

Vincenzi, S., G. Caramori, R. Rossi, and G.A. De Leo. 2006. A GIS-based habitat suitability model for commercial yield estimation of Tapes philippinarun in a Mediterranean coastal lagoon (Sacca di Goro, Italy). Ecological Modeling 193: 90-104.

Warren, M. L., Jr., and M. G. Pardew. 1998. Road crossings as barriers to small-stream fish movement. Transactions of the American Fisheries Society 127:637-644.

Weins, J.A. 2002. Riverine landscapes: taking landscape ecology into the water. Freshwater Biology 47: 501-515. 
Yoon, K. 1989. The propagation of errors in multiple-attribute decision analysis: a practical approach. The Journal of the Operational Research Society 40: 681686.

Yost, A.C., S.L. Petersen, M. Gregg, and R. Miller. 2008. Predictive modeling and mapping sage grouse (Centrocercus urophasianus) nesting habitat using maximum entropy and a long-term dataset from Southern Oregon. Ecological Informatics 3: 375-386.

Table 3.1: Summary of watersheds sampled with natural barrier occurrence shown as number of barriers and as barrier density, or number of barrier per stream kilometer.

\begin{tabular}{lcccc}
\hline \multicolumn{1}{c}{ Watershed } & $\begin{array}{c}\text { Number of } \\
\text { Barriers }\end{array}$ & Stream km & Barriers/km & State \\
\hline Adams & 31 & 6.6 & 4.70 & PA \\
Alicias & 12 & 2 & 6.00 & PA \\
Caledonia & 9 & 3 & 3.00 & PA \\
Conashaugh & 16 & 3 & 5.33 & PA \\
Dingmans & 14 & 11.5 & 1.22 & PA \\
Dunnfield & 23 & 6.4 & 3.59 & NJ \\
FBT (DC) & 32 & 1.3 & 24.62 & NJ \\
FBT (SP5) & 12 & 1.3 & 9.23 & NJ \\
Heller & 24 & 2.7 & 8.89 & PA \\
Hornbecks & 21 & 9 & 2.33 & PA \\
Mill & 22 & 4.4 & 5.00 & PA \\
Randall Vancampens & 22 & 3.8 & 5.79 & PA \\
Raymondskill & 20 & 6.7 & 2.99 & PA \\
Spackmans & 15 & 2.1 & 7.14 & PA \\
Toms & 28 & 11.3 & 2.48 & PA \\
Vancampens & 50 & 20.3 & 2.46 & NJ \\
White & 4 & 2.2 & 1.82 & NJ \\
\hline
\end{tabular}


Table 3.2: Comparison of barrier occurrence logistic regression models using AIC values. The AIC value of the most parsimonious model is highlighted in bold.

\begin{tabular}{lcccc}
\hline \multicolumn{1}{c}{ Model Name } & AIC & K & $\begin{array}{c}\text { Delta AlC } \\
(\boldsymbol{\Delta} \boldsymbol{i})\end{array}$ & $\begin{array}{c}\text { Akaike } \\
\text { Weight } \\
(\boldsymbol{W i})\end{array}$ \\
\hline Elevation+Aspect+Slope+Flow & & & & \\
Accumulation+Geology+Soil & 558.01 & 6 & 21.15 & 0.00 \\
Aspect+Slope+Flow Accumulation+Geology+Soil & 556.01 & 5 & 19.15 & 0.00 \\
Aspect+Slope+Flow Accumulation+Soil & 537.5 & 4 & 0.64 & 0.38 \\
Slope+Flow Accumulation+Geology+Soil & 555.2 & 4 & 18.34 & 0.00 \\
Slope+Flow Accumulation+Soil & 536.86 & $\mathbf{3}$ & $\mathbf{0}$ & $\mathbf{0 . 5 2}$ \\
Slope+Flow Accumulation & 554.19 & 2 & 17.33 & 0.00 \\
Slope+Soil & 541.84 & 2 & 4.98 & 0.04 \\
Flow Accumulation+Soil & 541.63 & 2 & 4.77 & 0.05 \\
Flow Accumulation & 579.65 & 1 & 42.79 & 0.00 \\
Slope & 559.61 & 1 & 22.75 & 0.00 \\
Soil & 546.99 & 1 & 10.13 & 0.00 \\
\hline
\end{tabular}

Table 3.3: Significant variable contributions to the most parsimonious barrier presence logistic regression model.

\begin{tabular}{lccc}
\hline \multicolumn{1}{c}{ Explanatory Variable } & Estimate & Standard Error & P-Value \\
\hline Slope & $2.305 \mathrm{E}-02$ & $9.35 \mathrm{E}-03$ & 0.0138 \\
Flow Accumulation & $-1.351 \mathrm{E}-07$ & $5.31 \mathrm{E}-08$ & 0.0109 \\
Soil Type OprE & $1.596 \mathrm{E}+00$ & $5.98 \mathrm{E}-01$ & 0.0076 \\
\hline
\end{tabular}




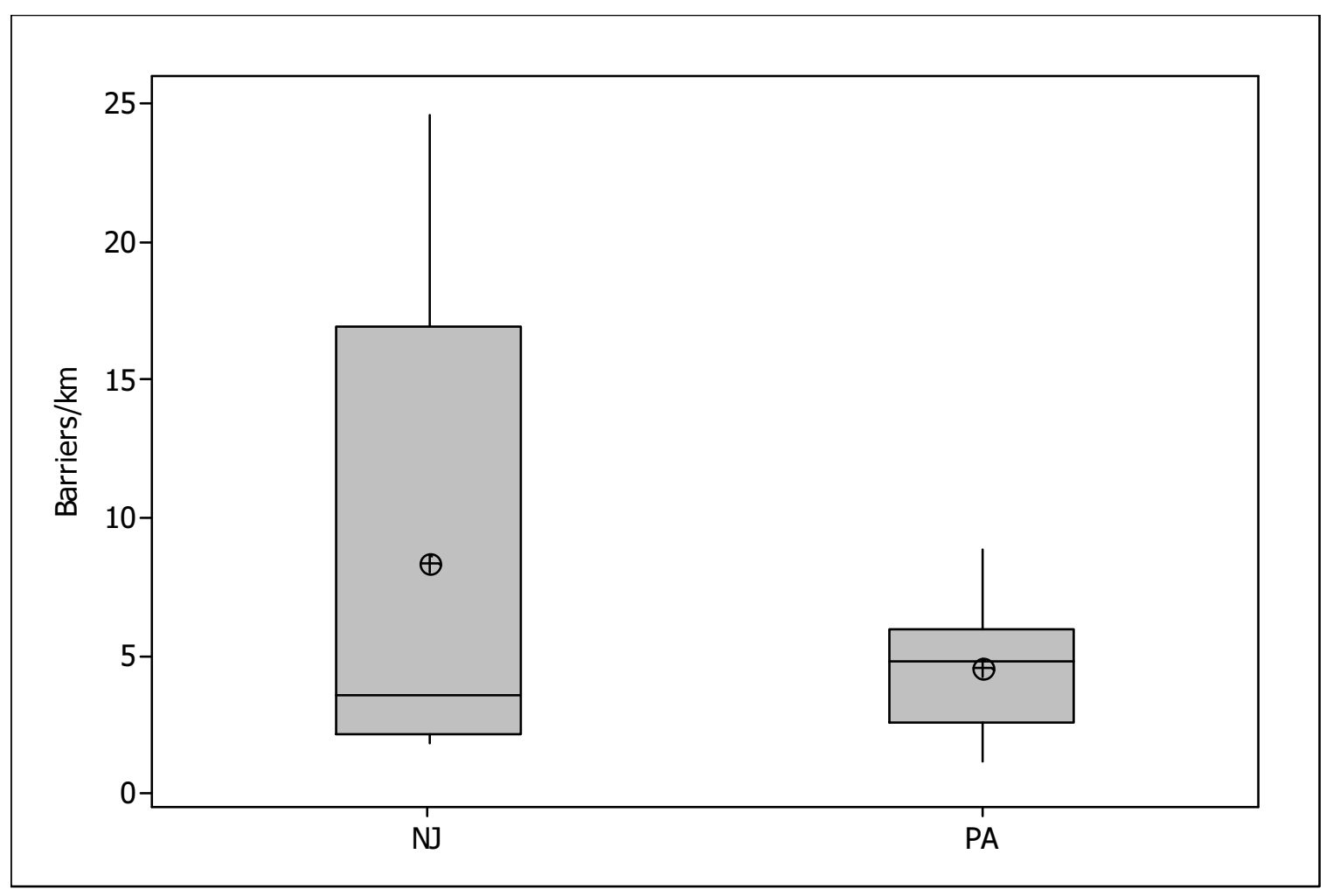

Figure 3.1: Comparison between natural barrier occurrences in sites in New Jersey (NJ) versus sites in Pennsylvania (PA). There is no significant difference $(\mathrm{P}=0.432)$ between states although New Jersey watersheds did have a higher average value. This is likely due to one high outlier with a large number of natural barriers per stream kilometer in a New Jersey watershed. Boxes represent interquartile range with a median bar while the bull's-eye represents the mean value for each group. Whiskers represent the full data range with minimum and maximum values. 


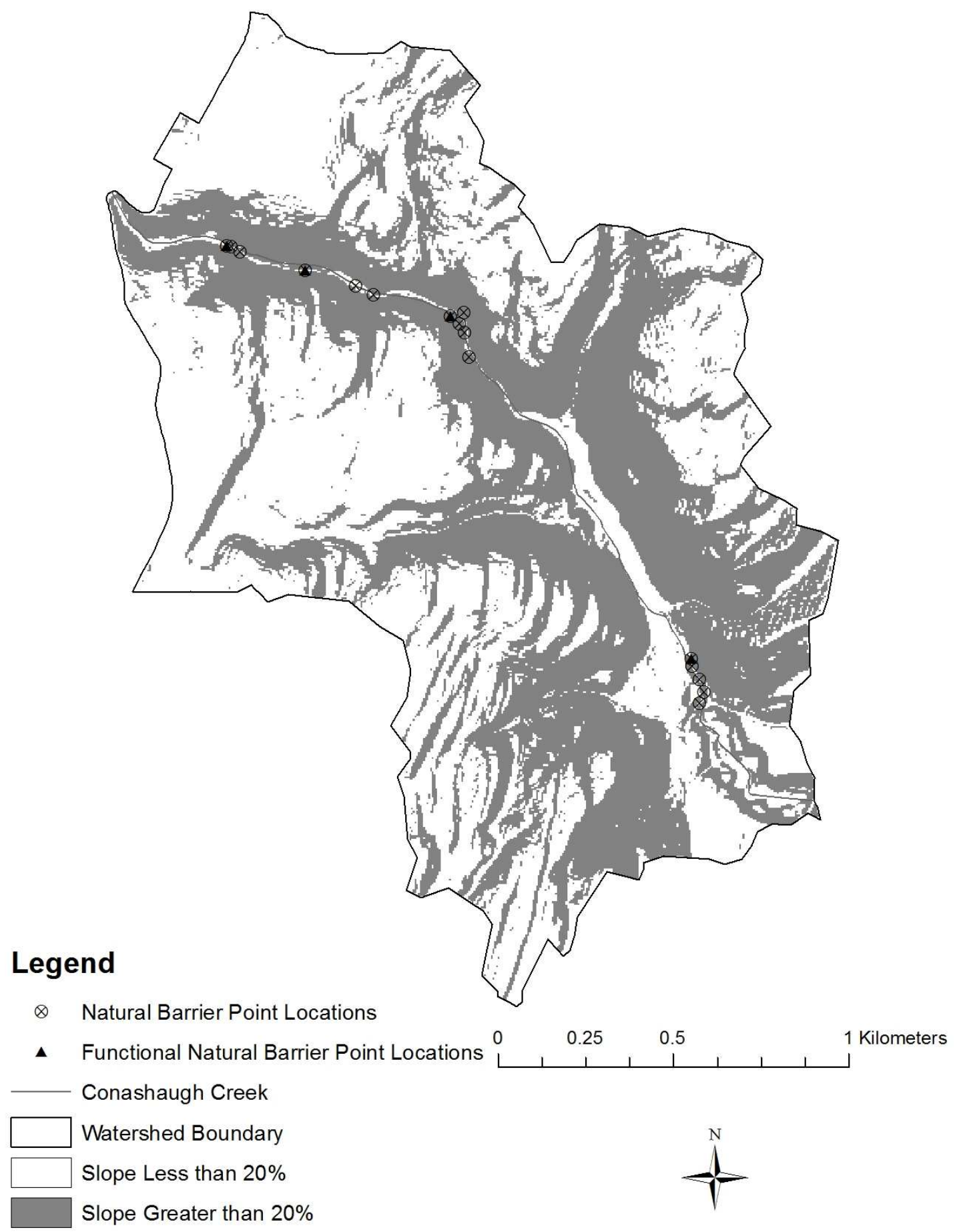

Figure 3.2: Map of Conashaugh Creek watershed showing application of rules criteria for mapping in raster calculator. Areas of high slope are identified and natural barrier occurrence shows a positive relationship to those areas that have high slope close proximity to the stream channel. 


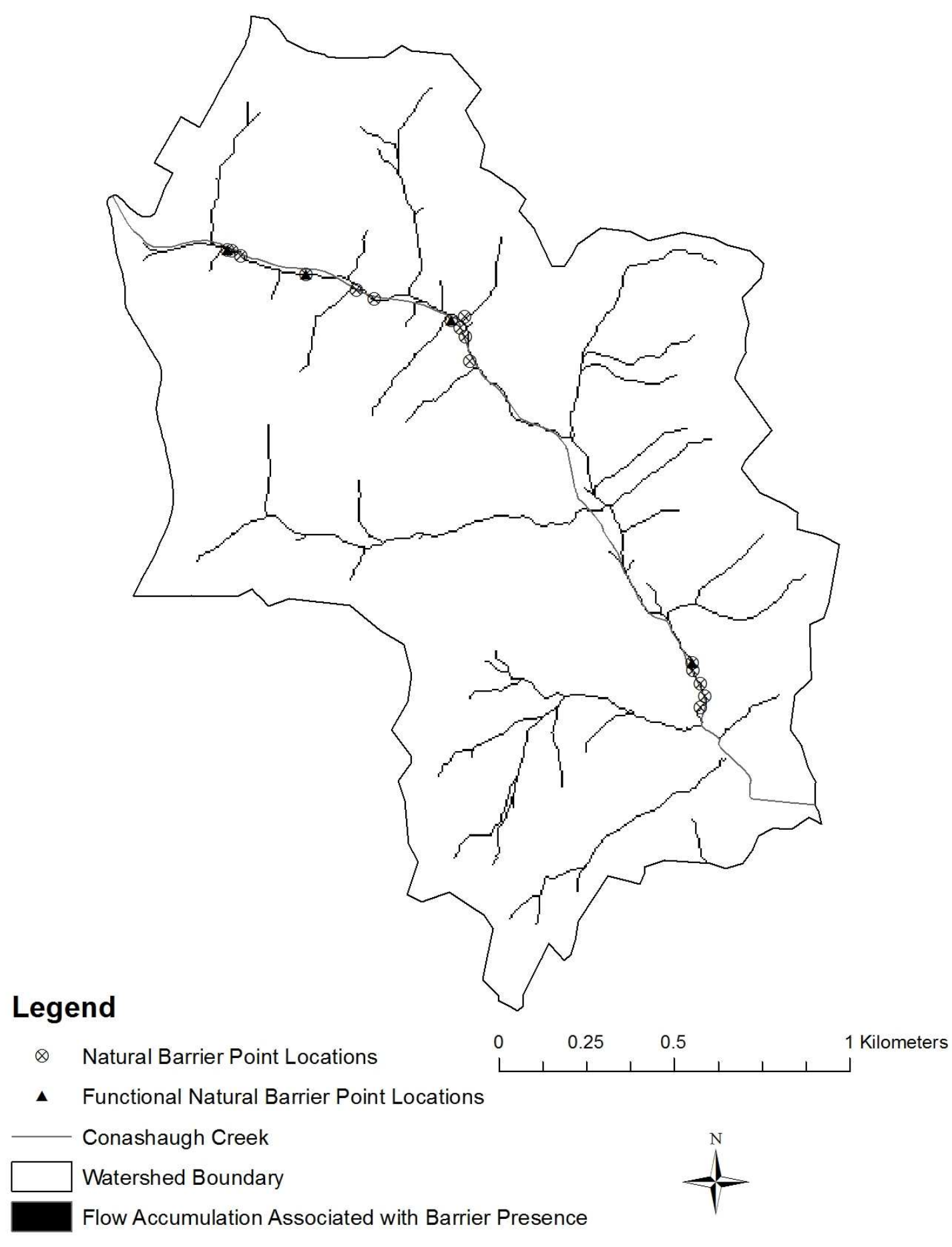

Figure 3.3: Map of Conashaugh Creek watershed showing application of rules criteria for mapping in raster calculator. Areas of suitable flow accumulation are shown as grids of black squares which form stream network patterns. Notice the lack of suitable flow accumulation areas near the mouth of this watershed in the southeast corner. These areas are not included in barrier occurrence likelihood because they represent the upper $20 \%$ of the watershed's flow accumulation values. These areas are not statistically associated with natural barrier occurrence and are therefore excluded from the rule criteria. 


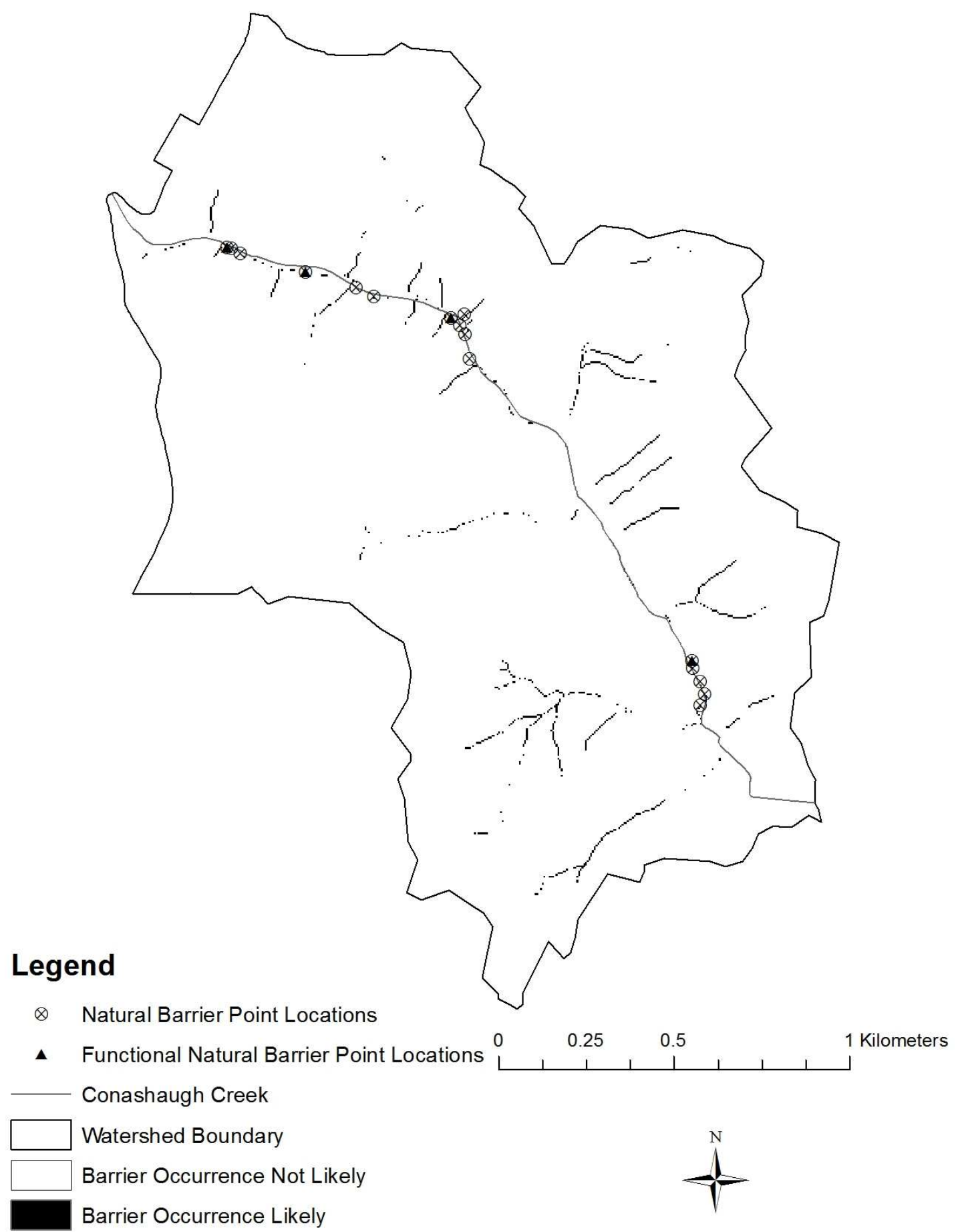

Figure 3.4: Final mapped output from the raster-based rules criteria for natural barrier occurrence. Areas with overlapping conditions for slope, flow accumulation, and soil type are shown as those dark areas where barrier occurrence is likely. This particular watershed does not contain the suitable soil type conditions and therefore shows no categorical component represented as large areas of suitability. 


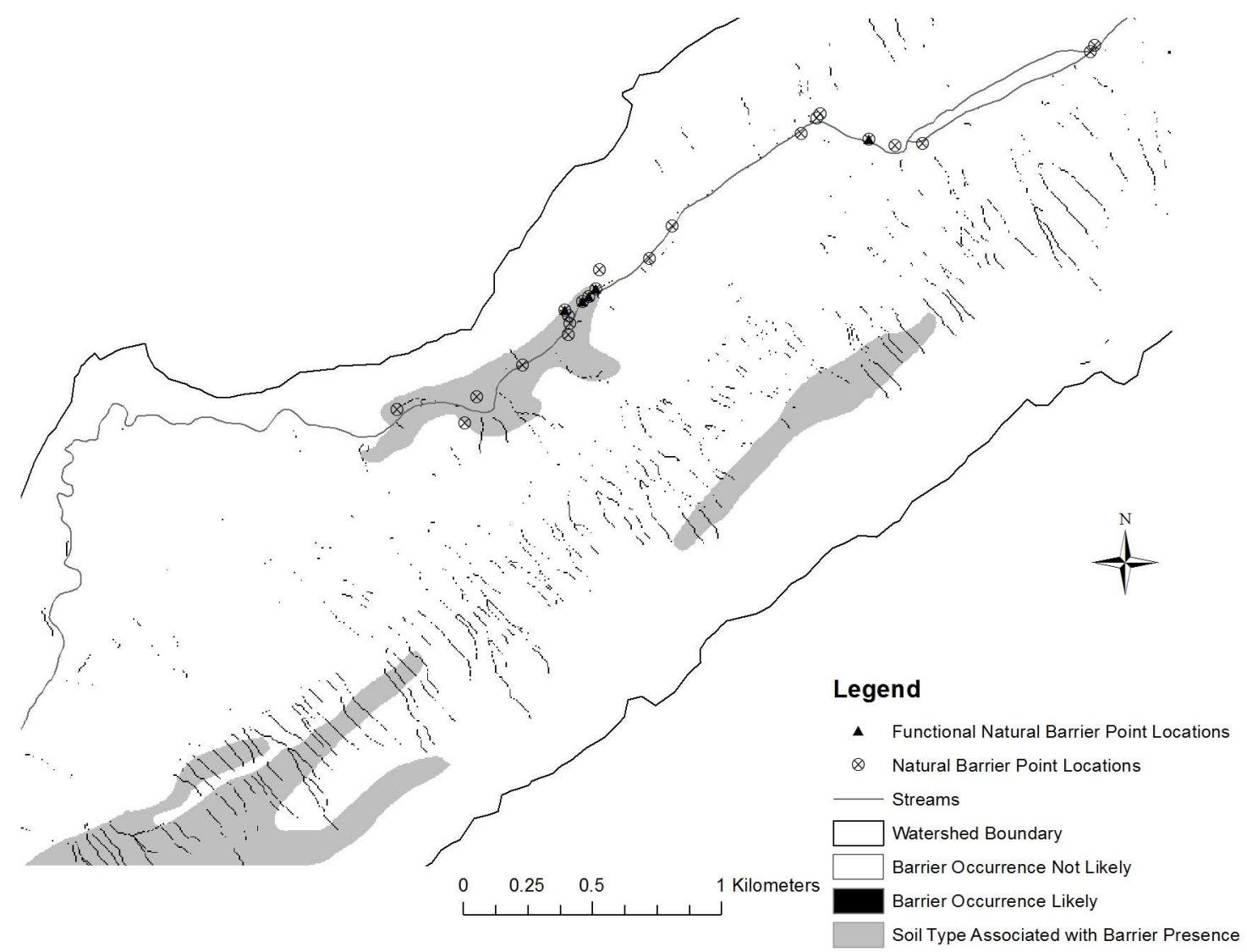

Figure 3.5: Final mapped output from the raster-based rules criteria for natural barrier occurrence. Areas with overlapping conditions for slope, flow accumulation, and soil type are shown as those dark areas where barrier occurrence is likely. This watershed contains the soil type associated with barrier presence. Those areas are shown in a light gray color and overlap with the actual stream in an area of high barrier occurrence. 